\title{
TEORIA NA ANTROPOLOGIA DESDE OS ANOS 60*,
}

Sherry B. Ortner

\begin{abstract}
Todo ano, perto da época em que a Associação Americana de Antropologia costuma se reunir, o New York Times convida um antropólogo de renome para escrever uma coluna de opinião sobre o estado da disciplina. Essas contribuições tendem a mostrar uma visão bastante sombria. Alguns anos atrás, por exemplo, Marvin Harris sugeriu que a antropologia estava sendo cooptada por místicos, fanáticos religiosos e membros de seitas californianas; que os encontros eram dominados por painéis sobre xamanismo, bruxaria, e "fenômenos anormais"; e que "trabalhos científicos baseados em estudos empíricos" tinham sido intencionalmente excluídos do programa (Harris 1978). Mais recentemente, num tom mais sóbrio, Eric Wolf sugeriu que o campo da antropologia está se desmembrando. Os subcampos (e os sub-subcampos) estão cada vez mais seguindo seus próprios interesses, perdendo contato uns
\end{abstract}

\footnotetext{
* Este ensaio contém muito da minha história intelectual. Não haverá contexto mais apropriado para agradecer aos meus professores Frederica de Laguna, Clifford Geertz e David Schneider por terem me transformado, por bem ou por mal, numa antropóloga. Eu gostaria também de agradecer aos seguintes amigos e colegas pelas úteis contribuições para o desenvolvimento deste ensaio: Nancy Chodorow, Salvatore Cucchiari, James Fernandez, Raymond Grew, Keith Hart, Raymond Kelly, David Kertzer, Robert Paul, Paul Rabinow, Joyce Riegelhaupt, Anton Weiler e Harriet Whitehead. Partes deste trabalho foram apresentadas no Departamento de Antropologia da Universidade de Princeton; no Departamento de Antropologia Social da Universidade de Stockholm; no Seminário de História das Ciências Sociais (fundado e coordenado por Charles e Louise Tilly) da Universidade de Michigan; no Seminário de Humanidades da Universidade de Stanford; e no Seminário de Teoria e Métodos em Estudos Comparativos (coordenado por Neil Smelser) na Universidade da Califórnia, Berkeley. Eu recebi valiosos comentários e reações em todos esses contextos
} 
com os outros e com o conjunto. Não há mais um discurso compartilhado, um conjunto compartilhado de termos que sirva de norteador para todos os antropólogos, uma linguagem compartilhada que todos nós falemos, mesmo que de forma idiossincrática (Wolf 1980).

O estado de coisas parece muito com o que Wolf descreve. O campo assemelha-se a um conjunto de trapos e retalhos de indivíduos e panelinhas dedicando-se a investigações díspares e falando principalmente entre eles mesmos. Nós sequer ouvimos discussões calorosas hoje em dia. Apesar de a antropologia nunca ter sido unificada no sentido de adotar um paradigma único compartilhado, houve ao menos uma época em que existiam algumas grandes categorias de filiação teórica, um conjunto de campos ou escolas identificáveis, e alguns epítetos simples que se podia lançar nos oponentes. Agora, mesmo neste plano o ânimo é apático. Nós não nos xingamos mais. Nós não temos mais certeza de onde estão as linhas de confronto, e onde deveríamos nos posicionar se pudéssemos identificar os lados.

Porém, como antropólogos, nós podemos reconhecer nisso tudo os sintomas clássicos da liminaridade - confusão de categorias, expressões de caos e antiestrutura. E sabemos que tal desordem pode ser a incubadora de uma ordem nova e possivelmente melhor. Realmente, se examinarmos o presente com maior atenção, poderemos até discernir nele o formato da nova ordem por vir. É isso que proponho fazer neste artigo. Eu argumentarei que um novo símbolo-chave de uma orientação teórica está emergindo, que pode ser rotulado como "prática" (ou "ação", ou "práxis"). Não se trata nem de uma teoria nem de um método em si, mas sim, como eu disse, de um símbolo, em nome do qual uma variedade de teorias e métodos vem sendo desenvolvida. Porém, para entender o significado desta tendência, devemos voltar pelo menos vinte anos atrás e ver onde nós começamos, e como chegamos onde estamos agora.

Contudo, antes de embarcarmos nesta tarefa, é importante especificar a sua natureza. Este ensaio se ocupará principalmente das relações entre várias escolas ou abordagens teóricas, tanto durante períodos específicos quanto ao longo do tempo. Nenhuma abordagem será descrita de maneira exaustiva ou discutida isoladamente; em vez disso, vários temas ou dimensões de cada abordagem serão realçados na medida em que se relacionem com as tendências de pensamento mais amplas em que estou interessada. Cada antropólogo ou antropóloga provavelmente encontrará por demais simplificada sua escola favorita, ou até distorcida, na medida em que eu escolhi enfatizar aspectos que não correspondem ao que normalmente esses profissionais consideram como seus traços teóricos mais importantes. Portanto, leitores em busca de discussões mais exaustivas sobre abordagens 
específicas e/ou discussões que partam de um ponto de vista mais interno às abordagens terão que procurar em outro lugar. O interesse aqui, novamente, é o de elucidar relações.

\section{Os anos 60: símbolo, natureza, estrutura}

Apesar de haver sempre alguma arbitrariedade ao escolher um ponto de partida para qualquer discussão histórica, eu decidi começar no início da década de 1960. Primeiro, foi quando eu comecei na disciplina, e como eu geralmente tomo como dada a importância de ver qualquer sistema, pelo menos parcialmente, do ponto de vista do ator, não vejo por que não unir teoria e prática desde o começo. Assim, está explícito que esta discussão procede não a partir de um ponto de vista externo hipotético, mas a partir da perspectiva deste ator específico atravessando a antropologia de 1960 até hoje.

Mas atores sempre atribuem universalidade às suas próprias experiências e interpretações. Eu sugeriria também que, num sentido relativamente objetivo, houve de fato um conjunto importante de revoluções na teoria antropológica que começou no início dos anos 60. Realmente, parece que tal agitação revisionista era característica de muitos campos naquela época. Na crítica literária, por exemplo,

a partir da década de 1960 uma mistura volátil de linguística, psicanálise e semiótica, estruturalismo, teoria marxista e estética da recepção começou a substituir o antigo humanismo moral. O texto literário caminhava para um status de fenômeno: um evento sócio-psico-cultural-linguístico e ideológico que surgia das competências linguísticas e taxonomias da ordem narrativa disponíveis, das permutações de gêneros, das opções sociológicas de formação estrutural, das restrições ideológicas da infraestrutura... [Havia] uma ampla e contenciosa percepção revisionista (Bradbury 1981:137).

Na antropologia do fim dos anos 50, o kit do bricoleur teórico consistia de três paradigmas principais algo exauridos - o funcionalismo estrutural britânico (herança de A. R. Radcliffe-Brown e Bronislaw Malinowski), a antropologia cultural e psicocultural norte-americana (herança de Margaret Mead, Ruth Benedict et al.), e a antropologia evolucionista norte-americana (centrada em torno de Leslie White e Julian Steward, e com vínculos fortes com a arqueologia). Porém, foi também durante os anos 50 que alguns dos atores e das turmas centrais da nossa história foram treinados em cada uma 
dessas áreas. Eles emergiram no começo dos anos 60 com ideias agressivas sobre como fortalecer os paradigmas de seus mentores e antecessores, assim como, aparentemente, com posições muito mais combativas vis-à-vis às outras escolas. Foi essa combinação de novas ideias e agressividade intelectual que lançou os três movimentos com os quais esta narrativa começa: a antropologia simbólica, a ecologia cultural, e o estruturalismo.

\section{Antropologia simbólica}

No período formativo — digamos 1963-1966 — os proponentes principais da "antropologia simbólica" nunca usaram esta expressão como um rótulo. Ao contrário, era uma etiqueta (provavelmente inventada pela oposição), um guarda-chuva para um número de tendências muito diversas. Duas de suas principais variantes parecem ter sido inventadas independentemente, uma por Clifford Geertz e seus colegas na Universidade de Chicago, e outra por Victor Turner em Cornell. ${ }^{2}$ As importantes diferenças entre os geertzianos e os turnerianos provavelmente não são plenamente conhecidas por aqueles fora da cena da antropologia simbólica. Enquanto Geertz era influenciado principalmente por Max Weber (através de Talcott Parsons), Turner era sobretudo influenciado por Emile Durkheim. Além disso, Geertz claramente representa uma transformação da antropologia americana anterior, debruçada principalmente sobre as formas de operar da "cultura", enquanto Turner representa uma transformação da antropologia britânica anterior, principalmente debruçada sobre as formas de operar da "sociedade".

A mudança teórica mais radical de Geertz (1973b) foi argumentar que a cultura não é algo preso dentro das cabeças das pessoas, mas que é incorporada em símbolos públicos, símbolos através dos quais os membros de uma sociedade comunicam sua visão de mundo, orientações de valor, ethos e tudo mais uns aos outros, às gerações futuras - e aos antropólogos. Com esta formulação, Geertz deu ao conceito de cultura, até então difícil de definir, um lócus relativamente fixo, e um grau de objetividade que não tinha anteriormente. Para Geertz e muitos outros, o foco nos símbolos foi heuristicamente liberador: mostrou-lhes onde encontrar o que eles queriam estudar. Entretanto, o interesse nos símbolos consistia em que eles eram, em última instância, veículos para significados; o estudo dos símbolos como tais nunca foi um fim em si mesmo. Deste modo, por um lado, os geertzianos ${ }^{3}$ nunca estiveram particularmente interessados em distinguir e catalogar as variedades de tipos simbólicos (sinais, signos, ícones, índices etc. — ver, por contraste, Singer 1980) nem, por outro lado (e em oposição à Turner, sobre 
quem nós iremos tratar em breve), estiveram interessados particularmente nos modos com que os símbolos desempenham certas operações práticas no processo social - sarar pessoas através de ritos de cura, transformar meninos e meninas em homens e mulheres através da iniciação, matar pessoas através da feitiçaria - e assim por diante. Geertzianos não ignoram esses efeitos sociais práticos, mas tais símbolos não têm sido seu foco principal de interesse. Antes, o foco mais duradouro da antropologia geertziana tem sido a questão de como os símbolos modelam os modos em que atores sociais veem, sentem e pensam sobre o mundo ou, em outras palavras, como os símbolos operam como veículos de "cultura".

Vale ainda a pena notar, antecipando a discussão sobre estruturalismo, que o interesse de Geertz sempre esteve voltado mais para o lado "ethos" da cultura do que para a "visão de mundo", mais para as dimensões afetivas e estilísticas do que para as cognitivas. É claro que enquanto é muito difícil (para não dizer improdutivo e, em última instância, equivocado) separar tão rigorosamente os dois lados, é possível, não obstante, distinguir a ênfase em um ou outro. Para Geertz, então (assim como, antes dele, para Benedict, especialmente), até o mais cognitivo ou intelectual dos sistemas culturais como os calendários balineses - é analisado não (apenas) para revelar um conjunto de princípios cognitivos estruturantes, mas (especialmente) para compreender a forma com que o jeito balinês de dividir o tempo se imprime sobre o seu senso de self, de relações sociais e de conduta, com um sabor culturalmente distinto, um ethos (1973e). ${ }^{4}$

A outra grande contribuição do esquema geertziano foi a insistência em estudar a cultura "do ponto de vista do ator" (p.ex. 1975). Novamente, isto não implica que nós devamos entrar "na cabeça das pessoas". O que isto significa, muito simplesmente, é que a cultura é um produto de seres socialmente atuantes tentando dar sentido ao mundo no qual eles se encontram, e se nós pretendemos dar sentido a uma cultura, nós devemos nos situar na posição a partir da qual ela foi construída. A cultura não é um sistema abstratamente ordenado, que derive sua lógica de princípios estruturais ocultos, ou de símbolos especiais que proveem as "chaves" para a sua coerência. Sua lógica — os princípios das relações que ocorrem entre seus elementos - deriva muito mais da lógica da organização da ação, de pessoas operando a partir do seio de certas ordens institucionais, interpretando suas situações com vistas a agir coerentemente nelas (1973d). Pode ser notado aqui, contudo, que enquanto a perspectiva centrada no ator é fundamental para o esquema de Geertz, ela não é sistematicamente elaborada: Geertz não desenvolveu uma teoria da ação ou da prática como tal. Entretanto, ele posicionou firmemente o ator no centro de seu modelo, e muito do trabalho 
posterior centrado na prática constrói-se sobre uma base geertziana (ou geertzo-weberiana), como veremos.

A outra figura principal da escola de antropologia simbólica de Chicago é David Schneider. Schneider, como Geertz, foi um produto de Parsons, e também se concentrou primordialmente em refinar o conceito de cultura. Mas seus esforços foram em direção à compreensão da lógica interna dos sistemas de símbolos e significados, através da noção de "símbolos nucleares", e também através de ideias parecidas com o conceito de estrutura de Claude Lévi-Strauss (p.ex., 1968, 1977). De fato, embora Geertz tenha usado repetidamente a expressão "sistema cultural", ele nunca prestou muita atenção aos aspectos sistêmicos da cultura, e foi Schneider quem desenvolveu esse lado do problema de forma muito mais completa. Schneider em seu próprio trabalho desvinculou a cultura da ação social muito mais radicalmente que Geertz. Mesmo assim, talvez precisamente porque a ação social ("prática", "práxis") foi tão radicalmente separada da "cultura" no trabalho de Schneider, ele e alguns de seus alunos estiveram entre os primeiros antropólogos simbólicos a ver a prática, em si mesma, como um problema (Barnett 1977; Dolgin, Kemnitzer \& Schneider 1977).

Victor Turner, por fim, tem uma origem intelectual bem diferente. Ele foi treinado na variante do estrutural-funcionalismo britânico de Max Gluckman, a qual foi influenciada pelo marxismo, e que enfatizava que o estado normal da sociedade não é de solidariedade e integração harmônica das partes, mas de conflito e contradição. Deste modo, a questão analítica não é de que modo a solidariedade é ajustada, reforçada e intensificada, como para os herdeiros diretos de Durkheim, mas de que modo é construída e mantida em primeiro lugar, acima e além dos conflitos e das contradições que constituem o estado normal das coisas. Para o leitor americano, isto pode parecer apenas uma variante menor do projeto funcionalista básico, já que para ambas as escolas a ênfase cai na manutenção da integração, e especificamente na manutenção da integração da "sociedade" — atores, grupos, o todo social - em oposição à "cultura". Mas Gluckman e seus alunos (incluindo Turner) acreditavam que suas diferenças em relação às correntes dominantes eram bem mais profundas. Além disso, eles sempre constituíram uma minoria dentro do establishment britânico. Esse pano de fundo é responsável em parte pela originalidade de Turner vis-à-vis a seus compatriotas, o que o levou eventualmente à invenção independente da sua própria marca de uma antropologia explicitamente simbólica.

Não obstante, apesar da relativa novidade do deslocamento de Turner em direção aos símbolos, existe em seu trabalho uma continuidade profunda das preocupações da antropologia social britânica e, consequentemente, 
profundas diferenças entre a antropologia simbólica turneriana e geertziana. Para Turner, os símbolos interessam não como veículos de e janelas analíticas para a "cultura" - o ethos integrado e a visão de mundo de uma sociedade mas como o que pode ser chamado de operadores no processo social, coisas que, quando colocadas juntas em certos arranjos em determinados contextos (especialmente rituais), produzem transformações que são essencialmente sociais. Desse modo, símbolos nos rituais de cura, iniciação ou caça ndembu são investigados para revelar os modos pelos quais eles deslocam os atores de um status a outro, resolvem contradições sociais e ligam os atores às categorias e às normas de sua sociedade (1967). Ao longo do caminho em direção a esses objetivos estrutural-funcionalistas bastante tradicionais, Turner, entretanto, identificou e trabalhou com certos mecanismos rituais, e alguns dos conceitos que ele desenvolveu se tornaram partes indispensáveis do vocabulário da análise do ritual - liminaridade, marginalidade, antiestrutura, communitas, e assim por diante $(1967,1969) .{ }^{5}$

Turner e os antropólogos simbólicos de Chicago não tiveram muito conflito entre eles, já que simplesmente, em grande parte, cada um trabalhou sem se dirigir diretamente ao outro. Além disso, os turnerianos ${ }^{6}$ acrescentaram uma dimensão importante, e tipicamente britânica, ao campo da antropologia simbólica como um todo, um senso da pragmática dos símbolos. Eles investigaram muito mais detalhadamente do que Geertz, Schneider et al., a "eficácia dos símbolos", a questão de como os símbolos de fato fazem aquilo que todos os antropólogos simbólicos dizem que fazem: operar como forças ativas no processo social (ver também Lévi-Strauss 1963; Tambiah 1968; Lewis 1977; Fernandez 1974).

Em retrospecto, pode-se dizer que a antropologia simbólica teve um número de limitações significativas. Eu me refiro não às acusações de que era não científica, mística, literária, frouxa e coisas semelhantes, acusações jogadas por adeptos da ecologia cultural (ver abaixo). Em vez disso, pode-se apontar para a ausência, na antropologia simbólica, especialmente em sua forma americana, de uma sociologia sistemática; seu senso pouco desenvolvido do político na cultura; e sua falta de curiosidade no que concerne à produção e à manutenção de sistemas simbólicos. Estes pontos serão discutidos com maior profundidade no curso deste artigo.

\section{Ecologia cultural ${ }^{7}$}

A ecologia cultural representou uma nova síntese e um desenvolvimento do evolucionismo materialista de Leslie White $(1943,1949)$, Julian Steward 
$(1953,1955)$ e V. Gordon Childe (1942). Suas bases remontam a Lewis Henry Morgan e E. B. Tylor no século XIX e, no final das contas, a Marx e Engels, apesar de muitos evolucionistas da década de 1950, por razões políticas compreensíveis, não terem dado ênfase à conexão marxista. ${ }^{8}$

White havia investigado o que veio a ser rotulado de "evolução geral", ou a evolução da cultura-em-geral, através da aplicação da noção de estágios de complexidade social e avanço tecnológico. Estes estágios foram subsequentemente refinados por Elman Service (1958) e por Marshall Sahlins e Elman Service (1960), através do famoso esquema bandos-tribos-chefias-estados. Os mecanismos evolutivos no esquema de White derivavam de eventos mais ou menos acidentais: invenções tecnológicas que possibilitaram uma "captura de energia" maior, e o crescimento populacional (e talvez a guerra e a conquista), que estimularam o desenvolvimento de formas mais complexas de organização e coordenação social/política. Steward (1953) atacou tanto o enfoque sobre a evolução da cultura-em-geral (como oposto a culturas específicas) quanto a ausência de um mecanismo evolutivo de operação mais sistemática. Em vez disso, ele enfatizou que culturas específicas evoluem em formas específicas no processo de adaptação a condições ambientais específicas, e que a aparente uniformidade dos estágios evolutivos é de fato uma questão de adaptações similares às condições naturais similares em diferentes partes do mundo.

Se a ideia de que a cultura é contida em símbolos públicos e observáveis era a chave para que a antropologia simbólica se liberasse da antropologia cultural norte-americana anterior, o conceito que teve um papel similar na ecologia cultural foi "adaptação" (ver Alland 1975 para um resumo). Assim como Geertz tinha anunciado que o estudo da cultura como incorporada em símbolos eliminava o problema de como adentrar a cabeça das pessoas, Sahlins proclamou que o foco na adaptação aos fatores ambientais seria um meio de deixar de lado fatores tão amorfos como as gestalten culturais e a dialética histórica (1964). Havia uma grande rejeição a estudos do funcionamento interno tanto da cultura na acepção norte-americana como da sociedade na acepção britânica. Dinâmicas internas eram vistas como de difícil quantificação, e mais difícil ainda era atribuir primazia causal a uma ou mais entre estas. No entanto, era fácil tratar os fatores externos do meio ambiente natural e social como "variáveis independentes" fixas e quantificáveis:

Por décadas, agora séculos, tem-se batalhado intelectualmente sobre qual o setor da cultura que é o decisivo para a mudança. Muitos entraram no torneio sob bandeiras diversas. Curiosamente, poucos foram vencidos. Leslie White 
defende o crescimento tecnológico como o setor mais responsável pela evolução cultural; Julian Huxley, com muitos outros, percebe "a visão que o homem tem do destino" como a força decisiva; o modo de produção e a luta de classes participam ainda do debate. Mesmo diferentes, estas posições convergem em um aspecto, ou seja: de que o impulso para o desenvolvimento é gerado de dentro para fora... O pleito em defesa das causas internas do desenvolvimento pode ser reforçado apontando para um mecanismo como a dialética hegeliana, ou pode apoiar-se de um modo menos seguro em um argumento oriundo da lógica... De qualquer modo, há sempre uma suposição irreal e vulnerável, de que as culturas são sistemas fechados... É precisamente sobre este ponto que a ecologia cultural oferece uma nova perspectiva... Ela desloca a atenção para a relação entre o interior e o exterior; ela entende a troca entre cultura e meio ambiente como a principal fonte de mudança evolutiva. Agora, qual visão prevalecerá não será decidido sobre um pedaço de papel... Mas se a adaptação vence sobre o dinamismo interno, será porque tem certa força intrínseca e óbvia. A adaptação é real, naturalística, ancorada naqueles contextos históricos das culturas que o dinamismo interno ignora (Sahlins 1964:135-36)..$^{9}$

A versão da ecologia cultural de Sahlins e Service, que a maior parte dos arqueólogos antropológicos também abraçou, era ainda fundamentalmente evolucionista. O uso principal do conceito de adaptação foi para explicar o desenvolvimento, a manutenção e a transformação das formas sociais. Mas havia outra variante da ecologia cultural, que se desenvolveu um pouco mais tarde, que veio a dominar a ala materialista na década de 1960. Sua posição, expressada com mais força por Marvin Harris (p.ex., 1966) e talvez mais elegantemente por Roy Rappaport (1967), baseou-se fortemente na teoria de sistemas. Reposicionou o enfoque analítico desviando-o da evolução, e passou a explicar a existência de partes específicas de culturas específicas em termos das funções adaptativas ou de manutenção do sistema daquelas partes. Assim, o ritual kaiko dos Maring impedia a degradação do ambiente natural (Rappaport 1967), o potlatch kwakiutl mantinha o equilíbrio da distribuição de comida entre segmentos tribais (Piddocke 1969), e a sacralidade das vacas na Índia protegia um elo vital na cadeia alimentar agrícola (Harris 1966). Nestes estudos, o interesse se deslocou do modo como o ambiente estimula (ou frustra) o desenvolvimento de formas sociais ou culturais para a questão dos modos em que as formas sociais e culturais funcionam para manter uma relação já existente com o ambiente. Foi este último tipo de estudo que veio a representar a ecologia cultural como um todo na década de 60 .

Só uma pessoa realmente desligada da teoria antropológica naquele momento não teria percebido o pungente debate entre os ecologistas culturais 
e os antropólogos simbólicos. Enquanto os ecologistas culturais acusavam os antropólogos simbólicos de serem mentalistas de cabeça confusa, envolvidos em voos de interpretação subjetiva pouco científicos e inverificáveis, os antropólogos simbólicos consideravam que a ecologia cultural estava envolvida com um cientificismo desatento e estéril, contando calorias e mensurando chuva, e teimosamente ignorando a única verdade que a antropologia presumivelmente tinha estabelecido naquele momento: que a cultura intermedeia todo o comportamento humano. A luta maniqueísta entre "materialismo" e "idealismo", abordagens "duras" e "leves", "êmica" interpretativa e "ética" explicativa dominou o campo por uma boa parte da década de 60, e em alguns lugares, por grande parte da década de 70.

O fato de que a maioria de nós pensava e escrevia em termos de tais oposições pode ter origem, ao menos parcialmente, em esquemas mais difundidos do pensamento ocidental: subjetividade/objetividade, natureza/ cultura, mente/corpo, e assim por diante. A própria prática do trabalho de campo talvez tenha contribuído para tal pensamento, baseada como está na paradoxal injunção de participar e observar ao mesmo tempo. Pode ser então que este tipo de construção polarizada do ambiente intelectual na antropologia esteja motivada muito profundamente tanto pelas categorias culturais como pelas formas de praticar a profissão, para poder ser completamente eliminada. Mas a luta emic / etic da década de 60 surtiu um número de efeitos infelizes, entre os quais não foi menor o de impedir uma autocrítica adequada de ambos os lados da cerca. Ambas as escolas puderam se deliciar com as falhas da outra, e não examinar a própria casa na procura de deficiências. De fato, ambos os lados eram fracos não somente por serem incapazes de lidar com o que o outro lado fazia (os antropólogos simbólicos ao renunciarem a toda pretensão de "explicação", os ecologistas culturais perdendo de vista os marcos de significado dentro dos quais as ações humanas acontecem); ambos também eram fracos em algo que nenhum deles fez, ou seja, alguma sociologia sistemática. ${ }^{10}$

Certamente, do ponto de vista da antropologia social britânica, toda a luta norte-americana era totalmente sem sentido, já que parecia deixar de fora o termo central necessário para qualquer discussão antropológica correta: a sociedade. Onde estavam os grupos sociais, as relações sociais, as estruturas sociais, as instituições sociais que medeiam tanto os modos em que as pessoas pensam ("cultura") quanto as maneiras com que as pessoas experimentam e agem sobre seu ambiente? Mas este tipo de questões não podia ser respondido (caso alguém as tivesse colocado) nos termos das categorias da antropologia social britânica, porque os britânicos estavam tendo suas próprias reviravoltas intelectuais, às quais nós iremos voltar em breve. 


\section{Estruturalismo}

O estruturalismo, invenção mais ou menos individual de Lévi-Strauss, foi o único paradigma verdadeiramente novo que se desenvolveu nos anos 60. Poderia até se dizer que é o único paradigma genuinamente original das ciências sociais (e das humanidades também, para o caso) que se desenvolveu no século vinte. Inspirado na linguística e na teoria da comunicação, e considerando-se influenciado por Marx e Freud, Lévi-Strauss arguiu que a desconcertante diversidade visível dos fenômenos sociais e culturais podia tornar-se inteligível ao se demonstrarem as relações que esses fenômenos compartilham com uns poucos princípios simples subjacentes. Ele procurou estabelecer a gramática universal da cultura, as maneiras em que são criadas (pelo princípio da oposição binária) as unidades do discurso cultural, e as regras segundo as quais as unidades (os pares de termos em oposição) são dispostas e combinadas para produzir os produtos culturais concretos (mitos, regras de casamento, organização totêmica dos clãs etc.) que os antropólogos registram. As culturas são fundamentalmente sistemas de classificação, e também conjuntos de produções institucionais e intelectuais construídas sobre esses sistemas de classificação que, ainda, operam sobre aqueles. Uma das mais importantes operações secundárias da cultura em relação às suas próprias taxonomias é precisamente mediar ou reconciliar as oposições que estão na base daquelas taxonomias.

Na prática, a análise estrutural procede procurando os conjuntos básicos de oposições que subjazem a algum fenômeno cultural complexo um mito, um ritual, um sistema de casamento - e mostra as maneiras em que o fenômeno em questão é ao mesmo tempo a expressão desses contrastes e sua reformulação, produzindo assim um enunciado culturalmente significativo, ou uma reflexão, sobre a ordem. Não obstante, mesmo sem a análise completa de um mito ou ritual, a mera enumeração dos conjuntos de oposições relevantes de uma cultura é considerada uma empresa útil, já que revela os eixos do pensamento e os limites do pensável dentro dessa cultura e outras culturas vinculadas a ela (p.ex., Needham 1973b). Mas a maior demonstração do poder da análise estrutural se vê no estudo de Lévi-Strauss, em quatro volumes, as Mitológicas (1964-71). Aqui o método permite organizar dados numa escala vasta (que inclui a maior parte da América do Sul indígena e partes da América do Norte nativa também), assim como explicar uma miríade de pequenos detalhes — por que a onça cobre a boca quando ri ou por que as metáforas sobre o mel descrevem a fuga da caça. A combinação de amplo escopo e detalhe minucioso é o que dá à obra seu grande poder. 
Tem-se discutido muito a questão de que, em última instância, LéviStrauss finca na estrutura da mente as estruturas que ele distingue sob a sociedade e a cultura. Tanto a própria questão como sua crítica talvez sejam algo irrelevante para os antropólogos. Parece indiscutível que todos os humanos e todas as culturas classificam. Isto, por sua vez, sugere uma propensão mental inata de algum tipo, mas não implica que algum esquema de classificação em particular seja inevitável, não mais do que o fato de todo ser humano comer motive um sistema universal de categorias alimentícias.

A contribuição duradoura do estruturalismo de Lévi-Strauss consiste na percepção de que uma multiplicidade exuberante, até mesmo uma aparente aleatoriedade, pode possuir uma unidade e uma sistematicidade mais profundas, derivadas da operação de um pequeno número de princípios subjacentes. É neste sentido que Lévi-Strauss afirma sua afinidade com Marx e Freud que, de modo semelhante, argumentam que sob a proliferação superficial das formas operam uns poucos mecanismos simples e relativamente uniformes (DeGeorge \& DeGeorge 1972). Tal percepção, por sua vez, nos permite distinguir muito mais claramente entre simples transformações, que operam dentro de uma estrutura dada, e a mudança real, a revolução se quiser, na qual a própria estrutura é transformada. Assim, apesar da base naturalística ou biologicista do estruturalismo, e apesar da predileção pessoal de Lévi-Strauss por considerar que plus ça change, plus c 'est la même chose, a teoria sempre teve implicações importantes para uma antropologia muito mais histórica e/ou evolutiva que aquela praticada pelo mestre. A obra de Louis Dumont, particularmente, desenvolveu algumas dessas implicações evolutivas ao analisar a estrutura do sistema de castas indiano, e ao articular algumas das profundas mudanças estruturais incluídas na transição da casta à classe (1965, 1970; ver também Goldman 1970; Barnett 1977; Sahlins 1981). ${ }^{11}$

O estruturalismo nunca foi muito popular entre os antropólogos norte-americanos. Apesar de no início ser visto (sobretudo pelos ecologistas culturais) como uma variação da antropologia simbólica, seus pressupostos centrais eram de fato bastante distantes daqueles dos antropólogos simbólicos (com a exceção parcial dos schneiderianos). Havia uma quantidade de razões para isso que só podem ser brevemente esquematizadas: 1. a ênfase puramente cognitiva da noção levistraussiana de significado, contra o interesse dos norte-americanos em ethos e valores; 2. a ênfase bastante austera de Lévi-Strauss na arbitrariedade do significado (todo significado é estabelecido por contraste, nada carrega qualquer significado em si mesmo) contra o interesse dos norte-americanos nas relações entre as formas dos construtos simbólicos e os conteúdos para os quais são veículos; ${ }^{12}$ e 3. o lócus explicitamente abstrato das estruturas, divorciadas em todos os aspectos das 
ações e das intenções dos atores, contra o ator-centrismo bastante consistente, mesmo que definido de modos variados, dos antropólogos simbólicos (novamente, Schneider é uma exceção parcial a este ponto). Por todas estas razões, e provavelmente outras, o estruturalismo não foi tão incorporado pelos antropólogos simbólicos norte-americanos como pode ter parecido à primeira vista. ${ }^{13}$ Foi-lhe atribuído o que poderia se chamar de status de parentesco fictício, principalmente pela sua tendência de focalizar em alguns dos mesmos domínios que os antropólogos simbólicos tomavam como próprios - mito, ritual, etiqueta etc.

O impacto principal do estruturalismo fora da França aconteceu na Inglaterra, entre alguns dos antropólogos sociais britânicos mais ousados (ver especialmente Leach 1966). Lévi-Strauss e os britânicos estavam, de fato, mais aparentados entre eles, nascidos de duas linhas de descendência a partir de Durkheim. De qualquer modo, o estruturalismo no contexto britânico sofreu um número de transformações importantes. Evitando a questão da mente e das estruturas universais, os antropólogos britânicos aplicaram a análise estrutural principalmente a sociedades específicas e a cosmologias específicas (p.ex., Leach 1966, 1969; Needham 1973a; Yalman 1969; este ponto também se aplica a Dumont 1970, na França). Eles também focalizaram com mais detalhe o processo de mediação de oposições, e produziram uma quantidade de reflexões bastante originais sobre anomalia e antiestrutura, especialmente Pureza e perigo de Mary Douglas (ver também Turner 1967, 1969; Leach 1964; Tambiah 1969).

No entanto, houve um modo importante em que muitos dos britânicos expurgaram o estruturalismo de um de seus traços mais radicais - a eliminação da distinção durkheimiana entre a "base" social e seu "reflexo" cultural. Lévi-Strauss havia defendido que se as estruturas míticas existiam em paralelo às estruturas sociais, não era porque o mito refletia a sociedade, mas porque tanto o mito quanto a organização social compartilhavam uma estrutura subjacente comum. Muitos dos estruturalistas britânicos (Rodney Needham é a principal exceção), por sua parte, voltaram-se para uma posição mais dentro da tradição de Durkheim e Marcel Mauss, e consideraram que o mito e o rito refletiam e resolviam "no nível simbólico" oposições tidas como fundamentalmente sociais. ${ }^{14} \mathrm{Na}$ medida em que o estruturalismo britânico se restringiu ao estudo do mito e do rito, então, foi-lhe possível inserir-se belamente na antropologia britânica sem ter um efeito muito profundo sobre ela. Ele se tornou sua versão da antropologia cultural ou simbólica, sua teoria da superestrutura. Foi só mais tarde, quando um olhar estrutural (marxista estrutural) se voltou sobre o conceito britânico de estrutura social, que as faíscas começaram a voar. 
Em diversos campos - linguística, filosofia, história — houve uma forte reação contra o estruturalismo no início dos anos 70. Duas características inter-relacionadas - a recusa da importância de um sujeito intencional no processo social e cultural, e a recusa a qualquer impacto significativo da história ou do "evento" sobre a estrutura - eram sentidas como especialmente problemáticas, para não dizer inaceitáveis. Os estudiosos começaram a elaborar modelos alternativos, nos quais tanto os agentes como os eventos tinham um papel mais ativo. Esses modelos, no entanto, não ocuparam um lugar muito importante na antropologia até finais da década de 70, e serão discutidos na seção final deste ensaio. Na antropologia, durante a maior parte da década, o próprio estruturalismo, com seus defeitos (e virtudes), tornouse a base de uma das escolas teóricas dominantes, o marxismo estrutural. Passamos agora a essa década.

\section{Os anos 70: Marx}

A antropologia da década de 1970 estava vinculada de forma muito mais óbvia e transparente aos eventos do mundo real do que aquela do período anterior. A partir do final da década de 1960, tanto nos Estados Unidos quanto na França (em menor grau na Inglaterra), movimentos sociais radicais emergiram em grande escala. Primeiro veio a contracultura, depois o movimento antiguerra e, em seguida, um pouco mais tarde, o movimento das mulheres: esses movimentos não afetaram unicamente o mundo acadêmico, mas se originaram em boa parte dentro dele. Tudo o que fazia parte da ordem existente foi questionado e criticado. $\mathrm{Na}$ antropologia, as primeiras críticas tomaram a forma de denúncias sobre as relações históricas entre a antropologia, por um lado, e o colonialismo e o imperialismo, por outro (p.ex., Asad 1973; Hymes 1974). Mas isso apenas arranhou a superfície. O problema passou rapidamente para a questão mais profunda da natureza dos nossos marcos teóricos e, especialmente, para o grau em que eles encarnam e levam adiante os pressupostos da cultura ocidental burguesa.

O símbolo que a nova crítica mobilizou e as alternativas teóricas oferecidas para substituir os modelos antigos foram de Marx. De todos os grandes antecedentes da ciência social moderna do século XIX, Marx tinha estado visivelmente ausente dos principais repertórios teóricos. A EStrutura da ação social de Parsons, um dos textos sagrados dos antropólogos simbólicos treinados em Harvard, fazia um levantamento do pensamento de Durkheim e de Weber e de dois teóricos da economia, Alfred Marshall e Vilfredo Pareto, cuja relevância principal naquele contexto parecia ser o 
fato de eles não serem Marx. Os britânicos, incluindo tanto os antropólogos simbólicos quanto os estruturalistas, ainda eram firmemente durkheimianos. Lévi-Strauss afirmava ter sido influenciado por Marx, mas passou um tempo até que alguém pudesse compreender o que ele quis dizer com isto. Mesmo os ecologistas culturais, os únicos autoproclamados materialistas na década de 60, referiam-se pouco a Marx; de fato, Marvin Harris repudiouo de forma explícita (1968). Não é preciso ser um analista muito sutil dos aspectos ideológicos da história intelectual para perceber que a ausência de uma influência marxista significativa antes dos anos 70 era um reflexo da política do mundo real, assim como o foi o surgimento de uma forte influência marxista na década de 70.

Havia pelo menos duas escolas marxistas de teoria antropológica distintas: o marxismo estrutural, desenvolvido principalmente na França e na Inglaterra, e a economia política, que surgiu primeiro nos Estados Unidos e, posteriormente, também na Inglaterra. Houve também um movimento que poderia ser chamado de marxismo cultural, concentrado principalmente em estudos históricos e literários, mas ele não foi incorporado pelos antropólogos até recentemente e, portanto, será abordado na seção final do ensaio.

\section{Marxismo estrutural}

O marxismo estrutural foi a única escola que se desenvolveu inteiramente dentro do campo da antropologia e, provavelmente por esta razão, foi também a que surtiu impacto primeiro. No marxismo estrutural, Marx foi usado para atacar e/ou repensar, ou no mínimo expandir, praticamente todos os esquemas teóricos da época - antropologia simbólica, ecologia cultural, antropologia social britânica e estruturalismo propriamente dito. Ele pretendia ser uma revolução intelectual total e, se ele não conseguiu se estabelecer como a única alternativa a tudo o que nós tivemos, ele certamente conseguiu revirar boa parte da sabedoria recebida. Isto não quer dizer que os próprios escritos dos marxistas estruturais tiveram necessariamente esse efeito (p.ex., Althusser 1971; Godelier 1977; Terray 1972; Sahlins 1972; Friedman, 1975), mas simplesmente que o marxismo estrutural foi a força original dentro da antropologia para a promulgação e a legitimação de "Marx", do "marxismo" e da "interpretação crítica" no discurso do campo como um todo (ver também Diamond 1979).

O avanço específico do marxismo estrutural sobre as formas de antropologia materialista que o antecederam consistiu em localizar as forças determinantes não no ambiente natural e/ou na tecnologia, mas especificamente 
em certas estruturas de relações sociais. Considerações ecológicas não foram excluídas, mas foram englobadas por e subordinadas à análise da organização social, sobretudo política, da produção. Desta maneira, a ecologia cultural foi atacada como "materialismo vulgar", que reforçaria em vez de desfazer a "fetichização" capitalista clássica das "coisas", a dominação dos sujeitos pelos objetos, em vez da sua dominação pelas relações sociais incorporadas e simbolizadas por esses objetos (ver especialmente Friedman 1974). As relações sociais chaves em questão, denominadas modo(s) de produção, não devem ser confundidas com a organização superficial das relações sociais tradicionalmente estudadas pelos antropólogos sociais britânicos: linhagens, clãs, metades, e todo o resto. Estas formas superficiais daquilo que os britânicos chamavam "estrutura social" são vistas como modelos nativos de organização social que foram comprados pelos antropólogos como a realidade, mas que na verdade escondem, ou ao menos correspondem só parcialmente, às relações assimétricas de produção que são ocultas e que impulsionam o sistema. Aqui, então, estava situada a crítica da antropologia social britânica tradicional (ver especialmente Bloch 1971, 1974, 1977; Terray 1975).

Além de criticar e rever tanto a ecologia cultural como a antropologia social britânica, os marxistas estruturais voltaram sua atenção para os fenômenos culturais. Ao contrário dos ecologistas culturais, os marxistas estruturais não desconsideraram as crenças culturais e as categorias nativas como irrelevantes para as operações reais ou objetivas da sociedade, ou tampouco procuraram mostrar que as crenças culturais aparentemente irracionais, tais como a vaca sagrada, na verdade tinham funções práticas adaptativas. Assim como a Nova Esquerda no mundo real levou mais a sério as questões culturais (estilo de vida, consciência) do que a Velha Esquerda tinha feito, os marxistas estruturais atribuíram aos fenômenos culturais (crenças, valores, classificações) pelo menos uma função central em seu modelo de processo social. Especificamente, cultura foi convertida em "ideologia", e considerada a partir do ponto de vista de seu papel na reprodução social: legitimando a ordem existente, mediando as contradições na base e mistificando as fontes de exploração e de desigualdade no sistema (O'Laughlin 1974; Bloch 1977; Godelier 1977).

Uma das virtudes do marxismo estrutural, então, era que em seu esquema havia um lugar para tudo. Recusando-se a ver as pesquisas sobre relações materiais e sobre "ideologia" como trabalhos opostos, esses antropólogos estabeleceram um modelo em que os dois "níveis" foram relacionados entre si através de um núcleo de processos sociais / políticos / econômicos. Nesse sentido, eles ofereceram uma mediação explícita entre os campos "materialista" e "idealista" da antropologia dos anos 60. A mediação foi um tanto mecânica, como vamos discutir daqui a pouco, mas pelo menos existiu. 
Mais importante, a meu ver, é que os marxistas estruturais trouxeram de volta à cena uma sociologia relativamente poderosa. Eles cruzaram as categorias da antropologia social britânica com as categorias marxistas, e vice-versa, e assim produziram um modelo ampliado de organização social ("modo de produção"), que depois passaram a aplicar sistematicamente a casos particulares. Enquanto outros marxismos enfatizavam quase exclusivamente as relações de organização político-econômica ("a produção"), os marxistas estruturais eram, afinal, antropólogos, treinados para prestar atenção ao parentesco, à descendência, ao casamento, ao intercâmbio, à organização doméstica, e assim por diante. Eles, portanto, incluíram esses elementos em suas considerações sobre as relações políticas e econômicas (muitas vezes dando-lhes um toque mais marxista ao chamá-los de "relações de reprodução"), e o efeito total foi o de produzir imagens ricas e complexas do processo social em casos específicos. Tendo em conta a escassez relativa, já mencionada, de análise sociológica detalhada nas várias escolas da década de 60, esta foi uma contribuição importante.

Apesar de tudo isso, pode-se reconhecer que, contudo, o marxismo estrutural sofreu alguns problemas. Por um lado, o estreitamento do conceito de cultura como "ideologia", que teve o poderoso efeito de permitir aos analistas conectarem concepções culturais a estruturas específicas de relação social, era excessivo, e colocou o problema de relacionar novamente a ideologia às concepções mais gerais da cultura. Por outro lado, a tendência para ver a cultura/ideologia principalmente em termos de mistificação deu à maioria dos estudos culturais ou ideológicos desta escola um decidido sabor funcionalista, já que o resultado dessas análises era mostrar como o mito, o ritual, o tabu e tudo mais mantinham o status quo. Finalmente, e mais grave, embora os marxistas estruturais oferecessem uma maneira de mediar os "níveis" materiais e ideológicos, de fato não contestaram a própria noção de que esses níveis são distinguíveis analiticamente, em primeiro lugar. Assim, apesar de criticarem a noção durkheimiana (e parsoniana) do "social" como a "base" dos sistemas, eles apenas ofereceram uma "base" mais profunda e alegadamente mais verdadeira e objetiva. Não obstante tentarem descobrir funções mais importantes para a "superestrutura" (ou a despeito de afirmarem que o que é a base e o que é a superestrutura varia culturalmente e/ou historicamente, ou mesmo às vezes, e de modo meio indeterminado, que a superestrutura é parte da base), eles continuaram a reproduzir a ideia de que é útil manter esse conjunto de caixinhas analíticas.

Nesse sentido, pode-se observar que o marxismo estrutural ainda estava muito enraizado nos anos 60. Enquanto ele injetou uma dose saudável de sociologia no esquema de categorias anterior, e enquanto essa mesma 
sociologia foi concebida de um modo relativamente original, os escaninhos básicos do pensamento da década de 60 não foram radicalmente revistos. Além disso, diferentemente da escola de economia política e outras abordagens mais recentes que serão discutidas em breve, o marxismo estrutural foi em boa medida não histórico, um fator que também o vinculava a formas anteriores de antropologia. De fato, pode-se supor que foi, em parte, esta confortável combinação de categorias e pressupostos antigos embrulhados em uma nova retórica crítica que tornou, naquela época, o marxismo estrutural tão atraente. Ele era em muitos sentidos o veículo perfeito para os acadêmicos que haviam sido treinados em uma época anterior, mas que na década de 70 estavam sentindo a força do pensamento e da ação críticos, força esta que estava explodindo em torno deles.

\section{Economia política}

A escola da economia política inspirou-se, sobretudo, nas teorias de sistemas mundiais e de subdesenvolvimento da sociologia política (Wallerstein 1976; Gunder Frank 1967). Ao contrário do marxismo estrutural, que geralmente se debruçou sobre sociedades ou culturas relativamente discretas, como faziam os estudos antropológicos convencionais, os economistas políticos têm mudado o foco para sistemas políticos / econômicos regionais de grande escala (p.ex., Hart 1982). Em geral, na medida em que têm procurado combinar este foco com o trabalho de campo em comunidades específicas ou microrregiões, as suas investigações têm adotado a forma de pesquisas sobre os efeitos da penetração capitalista nessas comunidades (p.ex., American Etnologist 1978; Schneider \& Schneider 1976). A ênfase sobre o impacto das forças externas e sobre as formas como as sociedades se transformam ou evoluem, em boa medida para se adaptarem a esse impacto, vincula de maneiras específicas a escola da economia política à ecologia cultural dos anos 60; de fato, muitos dos seus seguidores atuais foram treinados naquela escola (p.ex., Ross 1980). Mas enquanto na ecologia cultural da década de 60, que frequentemente estudava sociedades relativamente "primitivas", as forças externas consideradas importantes eram as do meio natural, para os economistas políticos da década de 70, que geralmente estudam camponeses, as forças externas que importam são aquelas do Estado e do sistema capitalista mundial.

Em nível teórico, os economistas políticos diferenciam-se parcialmente dos seus antecessores ecologistas culturais ao mostrarem maior vontade de incorporar as questões simbólicas ou culturais às suas pesquisas (p.ex., Schneider 1978; Riegelhaupt 1978). Especificamente, seus trabalhos ten- 
dem a focar os símbolos envolvidos no desenvolvimento de identidade de classe, ou de grupo, no contexto de lutas político-econômicas de diversos tipos. Desse modo, a escola da economia política sobrepõe-se à indústria da "etnicidade" - em plena expansão - embora a literatura neste último campo seja demasiado ampla e amorfa para que eu faça mais do que uma breve menção aqui. Em qualquer caso, a vontade que os economistas políticos mostram em prestar atenção aos processos simbólicos, mesmo de forma restrita, faz parte do abrandamento mais geral das velhas guerras dos anos 60 entre materialismo e idealismo.

A ênfase que esta escola colocou sobre processos regionais amplos é salutar, até certo ponto. Os antropólogos têm a tendência de tratar as sociedades, e mesmo as aldeias, como se elas fossem ilhas voltadas para si próprias, com pouca consciência dos sistemas de relações mais largos em que essas unidades estão inseridas. Ocasionais estudos (p.ex., Sistemas políticos da Alta Birmânia, de Edmund Leach) que veem a sociedade num contexto regional mais largo têm sido anomalias um tanto inclassificáveis (mesmo quando admiradas). Ignorar o fato de que os camponeses são parte de Estados e que mesmo as sociedades e as comunidades "primitivas" estão invariavelmente envolvidas em sistemas mais abrangentes de trocas de todo tipo, é deformar seriamente os dados. Os economistas políticos têm a virtude de nos relembrar isso.

Finalmente, aos economistas políticos deve ser dado crédito por enfatizarem fortemente a importância da história para o estudo antropológico. Eles não são os primeiros que fizeram isto, nem são os únicos que fazem isto atualmente, e eu direi mais sobre a aproximação entre antropologia e história nas conclusões deste ensaio. Mesmo assim, certamente os membros desta escola são os mais engajados com uma antropologia plenamente histórica e os que estão produzindo trabalhos sistemáticos, de forma contínua, nessa direção.

Do lado negativo, devemos reclamar, em primeiro lugar, que o modelo da economia política é econômico demais, materialista - no senso estrito demais. Ouve-se muito sobre salários, mercado, cash nexus, exploração econômica, subdesenvolvimento, e assim por diante, mas não o bastante sobre relações de poder, dominação, manipulação, controle e temas parecidos, com os quais aquelas relações econômicas estão entrelaçadas e que constituem, para os atores, a maior parte de sua dolorosa experiência da injustiça econômica. A economia política, em outras palavras, não é política o suficiente.

Minha principal objeção, contudo, está localizada num nível mais profundo do modelo teórico da economia política. Especificamente, entendo que a sua visão do mundo como determinado pelo capitalismo é no mínimo 
questionável, em especial para a antropologia. No cerne deste modelo está a suposição de que virtualmente tudo o que nós estudamos já foi afetado ("penetrado") pelo sistema mundial capitalista e que, portanto, a maior parte daquilo que nós vemos nos nossos trabalhos de campo e descrevemos nas nossas monografias tem de ser entendida como tendo sido formada em resposta a esse sistema. Talvez isto seja verdade para camponeses europeus mas, mesmo nesse caso, é preferível ao menos deixar a questão em aberto. Quando nós nos afastamos do "centro", contudo, o pressuposto torna-se de fato muito problemático. Uma sociedade, mesmo uma aldeia, tem sua própria estrutura e sua história, e isto também deveria fazer parte da análise tanto quanto as suas relações com o contexto mais abrangente no qual ela opera (Ver Joel Kahn 1980 para uma perspectiva mais equilibrada).

Os problemas derivados desta visão - do mundo como determinado pelo capitalismo - também afetam a visão da história adotada pelos economistas políticos. Frequentemente, a história é tratada como algo que vem, como um barco, de fora da sociedade em questão. Portanto, isto não nos permite obter a história dessa sociedade, mas o impacto da (nossa) história nessa sociedade. Muitas vezes, os relatos produzidos por tal abordagem são um tanto insatisfatórios em termos das preocupações antropológicas tradicionais: a organização e a cultura reais da sociedade em questão. É verdade que os estudos tradicionais tinham os seus próprios problemas no que diz respeito à história. Tipicamente, eles nos apresentavam um pequeno capítulo sobre "o pano de fundo histórico" no início, e um capítulo inadequado sobre "mudança social" no final. Os estudos de economia política invertem essa relação, mas só para criar o problema inverso.

Os economistas políticos, além do mais, tendem a situar-se, eles mesmos, mais no barco (capitalista) da história do que em terra. Na realidade, dizem que, de qualquer modo, nós nunca poderemos chegar a saber como era o outro sistema nos seus aspectos únicos e "tradicionais". O argumento desenrola-se da seguinte forma: ao nos darmos conta de que muito do que vemos como tradição é na realidade uma resposta ao impacto da ocidentalização, não só conseguimos uma imagem precisa do que se passa na realidade, como também sinalizamos os efeitos perniciosos do nosso próprio sistema sobre os outros. Esta visão igualmente se faz presente, embora mais num tom de raiva e/ou de desespero do que de pragmatismo, numa quantidade de trabalhos recentes que questionam filosoficamente se é possível conhecermos verdadeiramente o "outro" - o exemplo principal disso é Orientalismo de Edward Said (ver também Rabinow 1977; Crapanzano 1980; Riesman 1977).

A esta posição só podemos responder: tentem. O esforço é tão importante como o resultado, tanto para nossas teorias como para nossas práticas. 
A tentativa de ver outros sistemas com os pés no mesmo chão dos nativos é a base, talvez a única base, da contribuição propriamente antropológica para as ciências sociais. É essa nossa capacidade, sobretudo desenvolvida no trabalho de campo, de adotar a perspectiva do povo em terra firme que nos permite aprender qualquer coisa - mesmo na nossa própria cultura para além do que nós já sabemos (de fato, enquanto um número crescente de antropólogos está fazendo trabalho de campo nas culturas ocidentais, inclusive nos Estados Unidos, a importância de manter a capacidade de perceber a alteridade, mesmo aqui perto, está cada vez mais clara). É essa nossa localização "no chão" que nos permite ver as pessoas não simplesmente como reprodutores e reagentes passivos a um "sistema", mas como agentes ativos e sujeitos da sua própria história.

Ao concluir esta seção, eu devo confessar que o meu ato de posicionar a escola da economia política nos anos 70 seja talvez uma ação ideológica. De fato, a economia política está mais do que viva na década de 80, e provavelmente se desenvolverá por mais algum tempo. Desta forma, a minha periodização está, como todas as histórias, apenas parcialmente relacionada com o tempo real. Eu incluí a economia política e o marxismo estrutural nesse período/categoria porque ambas as escolas continuam a compartilhar um conjunto de suposições distintas das que eu pretendo destacar para a antropologia da década de 80. Especificamente, ambas pressupõem, junto com algumas antropologias prévias, que a ação humana e o processo histórico estão determinados estrutural ou sistemicamente quase por inteiro. Seja a mão escondida da estrutura ou o rolo compressor do capitalismo o que seja visto como o agente da sociedade/história, certamente não são pessoas reais fazendo coisas reais. É precisamente deste tipo de abordagem que ao menos alguns antropólogos, assim como muitos profissionais de vários outros campos, parecem estar lutando para se livrar, à medida que nos adentremos na presente década.

\section{Entrando nos anos 80: prática}

Eu iniciei este artigo evidenciando a aparente exatidão da declaração de Wolf de que o campo da antropologia está se desintegrando, mesmo levando em consideração o baixo grau de integração que havia no passado. Também sugeri que podemos encontrar disseminados nessa paisagem os elementos de uma nova tendência que parece estar ganhando força e coerência. Nesta seção final chamo a atenção para essa nova tendência, faço um esboço dela e a submeto a uma crítica preliminar. 
Nos últimos anos, tem havido um crescente interesse em análises centradas em algum termo de um grupo de termos inter-relacionados, a saber: prática, práxis, ação, interação, atividade, experiência, performance. Um segundo grupo de termos, muito próximos àqueles, coloca o enfoque sobre quem realiza as ações: agente, ator, pessoa, self, indivíduo, sujeito.

Em alguns campos, o movimento nessa direção começou relativamente cedo, nos anos 70, parcialmente como uma reação direta ao estruturalismo. $\mathrm{Na}$ linguística, por exemplo, havia uma rejeição precoce ao estruturalismo linguístico e um forte movimento para enxergar a linguagem como comunicação e performance (p.ex., Bauman \& Sherzer 1974; Cole \& Morgan 1975). Na antropologia também houve apelos para uma abordagem mais centrada na ação. Na França, Pierre Bourdieu publicou seu Esboço da teoria da prática em 1972. Nos Estados Unidos, Geertz atacou tanto os estudos de sistemas simbólicos hipercoerentes (muitos dos quais inspirados nos seus próprios artigos programáticos), quanto o que ele entendeu como o formalismo estéril do estruturalismo; em lugar disso, conclamou os antropólogos a verem "o comportamento humano... como... ação simbólica" (1973a:10; ver também Dolgin, Kemnitzer \& Schneider 1977; Wagner 1975; T. Turner 1969). $\mathrm{Na}$ Inglaterra, havia uma ala minoritária que criticava as visões tradicionais de "estrutura social", não do ponto de vista do marxismo estrutural, mas da perspectiva da escolha individual e do processo de tomar decisões (e.g. Kapferer 1976). ${ }^{15}$

No entanto, na maior parte dos anos 70, os marxistas estruturais e, depois, os economistas políticos continuaram dominantes, pelo menos no campo da antropologia. Para eles, os fenômenos culturais e sociais deviam ser explicados referenciando-os a mecanismos sistêmico-estruturais de diversos tipos. Foi somente no final dos anos 70 que a hegemonia do marxismo estrutural, mas não da economia política, começou a ceder. Uma tradução inglesa do livro de Bourdieu foi publicada em 1978, e foi nesse período que os pedidos para uma abordagem orientada para a prática ficaram mais audíveis. Eis alguns exemplos:

Os instrumentos do processo de raciocinar estão mudando e a sociedade é representada cada vez menos como uma máquina sofisticada ou um quase organismo e cada vez mais como um jogo sério, um espetáculo de rua, ou um texto comportamental (Geertz 1980a:168).

Precisamos ver esses sistemas [de parentesco] em ação, estudar táticas e estratégias, e não simplesmente as regras do jogo (Barnes 1980:301). 
[...] concepções de gênero em qualquer sociedade devem ser entendidas como aspectos funcionais de um sistema cultural através dos quais os atores manipulam, interpretam, legitimam e reproduzem os padrões [...] que ordenam seu mundo social (Collier \& Rosaldo 1981:311). ${ }^{16}$

O que os atores querem e como podem obtê-lo? (Ortner 1981:366).

Se expandirmos a análise estrutural/semiótica para a antropologia geral baseados no modelo da sua relevância para a "linguagem", então aquilo que se perde não é somente a história e a mudança, mas a prática - a ação humana no mundo. Alguns podem até pensar que o que se perde é aquilo que é o mais próprio da antropologia (Sahlins 1981:6).

Como ocorreu no caso da forte tendência revisionista nos anos 60, o movimento atual parece estender-se bem além do campo próprio da antropologia. Em linguística, Alton Becker, em seu muito citado artigo, tem preferido enfatizar questões do processo de construir textos em vez da reificação de O Texto (1979). Em sociologia, parece que o interacionismo simbólico e outras formas da assim chamada microssociologia estão atraindo novas atenções, ${ }^{17}$ e Anthony Giddens confere à relação entre estrutura e "agência" o estatuto de um dos "problemas centrais" da moderna teoria social (1979). Na história, E. P. Thompson critica duramente os teóricos (de parsonianos a stalinistas) que tratam "a história como 'um processo sem sujeito' [e] que concordam com a erradicação da agência humana da história" (1978:79). Nos estudos literários, Raymond Williams insiste em que a literatura deve ser tratada como o produto de práticas específicas, e acusa aqueles que abstraem a literatura da prática de realizar "uma proeza ideológica extraordinária" (1977:46). E se forçarmos mais um pouco - e aqui estamos nos limites de um terreno perigoso - poderemos até ver todo o movimento da sociobiologia como parte dessa tendência geral, na medida em que transforma o mecanismo evolutivo de uma mutação aleatória numa opção intencional por parte dos atores que buscam maximizar seu sucesso reprodutivo (eu devo dizer logo aqui, e não em nota de rodapé, que tenho um grande número de objeções muito fortes à sociobiologia. No entanto, penso que não é tão irreal entender sua emergência como parte do amplo movimento para o qual estou chamando a atenção aqui).

A abordagem da prática é diversa, e não vou tentar comparar e contrastar suas muitas linhas. Pelo contrário, vou selecionar para discussão um número de trabalhos que parecem compartilhar uma orientação comum dentro do conjunto, uma orientação que se me afigura particularmente promissora. 
Eu não desejo canonizar qualquer um destes trabalhos, nem desejo atribuir um rótulo ao subconjunto e, desse modo, conferir-lhe maior grau de realidade do que já possui. O que faço aqui se parece mais com o início da revelação de uma fotografia, fazer com que uma forma latente se transforme em algo reconhecível.

Podemos começar por contrastar, de forma geral, (este subconjunto de) trabalhos mais recentes orientados para a prática com certas abordagens mais bem estabelecidas, especialmente com o interacionismo simbólico em sociologia (Blumer 1962; Goffman 1959; ver também Berreman 1962, e mais recentemente Gregor 1977 em antropologia) e com o que foi chamado transacionalismo em antropologia (Kapferer 1976, Marriott 1976; Goody 1978; Barth 1966; Bailey 1969). O primeiro ponto a sublinhar é que essas abordagens eram elaboradas em oposição à visão dominante, essencialmente parsoniana/durkheimiana, do mundo como ordenado por regras e normas. ${ }^{18}$ Mesmo reconhecendo que a organização institucional e os padrões culturais existem, os interacionistas simbólicos e os transacionalistas buscaram minimizar ou pôr entre parênteses a relevância desses fenômenos para entender a vida social:

Do ponto de vista da interação simbólica, a organização social é uma estrutura dentro da qual unidades atuantes desenvolvem suas ações. Aspectos estruturais tais como "cultura", "sistemas sociais", "estratificação social", ou "papéis sociais" estabelecem condições para a ação, mas não determinam essa ação (Blumer 1962:152).

Os mais novos teóricos da prática, por outro lado, compartilham a visão de que "o sistema" (em uma variedade de sentidos discutidos abaixo) tem de fato um efeito poderoso, até determinante, sobre a ação humana e sobre a forma dos eventos. Portanto, o seu interesse no estudo da ação e da interação não é uma questão de minimizar ou negar esse ponto mas, pelo contrário, expressa uma necessidade urgente de entender de onde vem "o sistema" - como é produzido e reproduzido, e como poderia ter mudado no passado ou ser mudado no futuro. Como Giddens argumenta em seu importante e recente livro (1979), o estudo da prática não é uma alternativa que se oponha ao estudo de sistemas ou estruturas, mas um complemento necessário dele.

O outro aspecto principal da mais recente orientação para a prática, que a distingue significativamente das antigas abordagens interacionistas e transacionalistas, reside em uma influência marxista palpável herdada dos anos 70. Em parte isto é visível na maneira em que são abordadas coisas 
como a cultura e/ou a estrutura, ou seja, embora os teóricos mais recentes da prática compartilhem com a antropologia dos anos 60 um sentido forte do poder modelador da cultura/estrutura, esse poder modelador é visto de modo sombrio, como uma forma de "constrangimento", "hegemonia" e "dominação simbólica". Nós voltaremos a esta posição com maior detalhe mais tarde. De forma mais geral, percebe-se a influência marxista no pressuposto de que as formas de ação ou interação mais importantes, para finalidades analíticas, são aquelas que ocorrem em relações assimétricas ou dominadas, ou seja, naquelas maneiras de ação ou interação que melhor explicam a forma de qualquer sistema em qualquer momento determinado. Seja uma questão de enfocar diretamente na interação (até mesmo na "luta") entre atores assimetricamente relacionados, seja na questão mais ampla de definir os atores (o que quer que seja que eles estejam fazendo) em termos dos papéis e dos status derivados das relações assimétricas das quais participam, a abordagem tende a destacar a assimetria social como a dimensão mais importante tanto da ação como da estrutura.

Nem todo o trabalho atual sobre a prática manifesta influência marxista. Parte dele - tal como os próprios interacionismo simbólico e o transacionalismo - acompanha mais o espírito de Adam Smith. Os membros do subconjunto que me interessa, entretanto, pelo menos compartilham, implícita ou explicitamente, o sabor crítico da antropologia dos anos 70, quando não uma fidelidade sistemática à própria teoria marxista.

Contudo, falar de uma influência marxista é realmente obscurecer um aspecto importante do que está acontecendo: uma interpenetração, quase uma fusão, entre esquemas marxistas e weberianos. Nos anos 60, a oposição entre Marx e Weber havia sido enfatizada como "materialista" e "idealista". Os teóricos da prática, em contraste, remetem a uma série de autores que interpretam o corpus marxista de modo a torná-lo compatível com as opiniões de Weber. Assim como Weber pôs o ator no centro de seu modelo, esses autores também enfatizam questões da práxis humana em Marx. Da mesma forma que Weber subsumiu o econômico no político, esses autores também incluem a exploração econômica na dominação política. E assim como Weber estava centralmente interessado no ethos e na consciência, esses autores também destacam questões similares no trabalho de Marx. Escolher Marx em vez de Weber como o teórico de referência de alguém é uma jogada tática de um determinado tipo. Na realidade, o marco teórico em questão deve quase tanto a um quanto ao outro (Sobre teoria, ver Giddens 1971; Williams 1976; Avineri 1971; Ollman 1971; Bauman 1973; Habermas 1973; Goldmann 1977. Para análises de caso substantivas nesta veia weberiano-marxista, ver Thompson 1966; Williams 1973; Genovese 1976.) 
Em seguida, apresentarei e avaliarei a posição da "nova prática" colocando uma série de questões: O que a abordagem da prática procura explicar? O que é prática? Como é motivada? E que tipos de relacionamentos analíticos são postulados no modelo? Deixem-me enfatizar muito fortemente que eu não ofereço aqui uma teoria da prática coerente. Eu meramente classifico e discuto, de uma forma bem preliminar, alguns dos eixos centrais de tal teoria.

\section{O que está sendo explicado?}

Como indicado previamente, a moderna teoria da prática busca explicar o(s) vínculo(s) estabelecido(s) entre a ação humana, por um lado, e alguma entidade global que poderíamos chamar de "o sistema", por outro. Perguntas a respeito destas relações poderiam ir nas duas direções - o impacto do sistema sobre a prática, e o impacto da prática sobre o sistema. Como funcionam esses processos será retomado mais adiante. Aqui devemos dizer algumas palavras sobre a natureza do "sistema".

Em dois trabalhos recentes na antropologia, que de forma explícita tentam elaborar um modelo baseado na prática (Bourdieu 1978 [1972]; e Sahlins 1981), os autores adotam nominalmente uma visão estruturalista francesa do sistema (padrões de relações entre categorias, e de relações entre relações). Apesar disso, de fato, tanto o habitus de Bourdieu quanto os "dramas cosmológicos" de Sahlins comportam-se em muitos sentidos como o conceito norte-americano de cultura ao combinarem elementos de ethos, afeto e valor com esquemas de classificação mais estritamente cognitivos. A escolha de uma perspectiva francesa ou norte-americana sobre o sistema sem dúvida tem certas consequências para a forma da análise como um todo; todavia, aqui não iremos focar tais consequências. O ponto é que os antropólogos da prática pressupõem que a sociedade e a história não são simplesmente uma soma de respostas ad hoc e de adaptações a estímulos particulares, mas que são governadas por esquemas organizacionais e avaliativos. São estes (incorporados, é claro, às formas institucionais, simbólicas e materiais) que constituem o sistema.

O sistema, ainda, não é dividido em unidades como base e superestrutura, ou sociedade e cultura, mas é uma totalidade relativamente inconsútil. Uma instituição - digamos, um sistema de casamento - é ao mesmo tempo um sistema de relações sociais, arranjos econômicos, processos políticos, categorias culturais, normas, valores, ideais, padrões emocionais, e assim por diante. Nenhuma tentativa é feita para sistematizar estes componentes em 
diversos níveis e atribuir primazia a um ou outro nível. Nem, por exemplo, se atribui o casamento como um todo à "sociedade", nem se atribui a religião à "cultura". Uma abordagem da prática não precisa romper o sistema em pedaços artificiais como base e superestrutura (e ainda discutir qual determina qual), pois o esforço analítico não consiste em explicar uma parte do sistema referindo-se à outra, mas explicar o sistema como um todo integral (o que não implica dizer que o sistema seja um todo harmoniosamente integrado) referindo-o à prática.

Mas se o sistema é um todo integral, ao mesmo tempo todas as suas partes ou dimensões não têm significado analítico equivalente. No núcleo do sistema, tanto conformando-o como deformando-o, existem as realidades específicas da assimetria, da desigualdade e da dominação em qualquer momento e lugar. Raymond Williams, um historiador marxista da literatura / cultura, resume a insistência no holismo e a posição privilegiada da dominação característica desta perspectiva. Tomando de Gramsci o termo "hegemonia" como o seu rótulo para o sistema, ele argumenta que

"hegemonia" é um conceito que ao mesmo tempo inclui e supera dois poderosos conceitos anteriores: o de "cultura" como um "processo social total", no qual os homens definem e moldam as suas vidas inteiras; e o de "ideologia" em qualquer dos sentidos marxistas, em que um sistema de significados e valores é a expressão ou a projeção de um interesse de classe particular.

"Hegemonia" vai além de "cultura" na sua insistência em relacionar o "processo social total" a distribuições específicas de poder e influência. Dizer que os homens definem e moldam as próprias vidas é verdade só em abstrato. Em qualquer sociedade atual existem desigualdades específicas nos meios e, portanto, na capacidade de realizar esse processo... Assim Gramsci introduz o necessário reconhecimento da dominação e da subordinação em algo que, no entanto, ainda tem que ser reconhecido como um processo integral.

É justamente neste reconhecimento do caráter integral do processo que o conceito de "hegemonia" supera o de "ideologia". O que é decisivo não é só o sistema consciente de ideias e crenças, mas o processo social vivido inteiro como organizado na prática por significados e valores específicos e dominantes...

[Hegemonia] é no seu sentido mais forte, uma "cultura", mas trata-se de uma cultura que tem que ser vista também como a dominação e a subordinação vividas por classes particulares (Williams 1977:108-109, 110).

Então, o que uma teoria da prática procura explicar é a gênese, a reprodução e a mudança de forma e significado de um "todo" social/cultural dado, definido - mais ou menos - neste sentido. 


\section{O que é prática?}

Em princípio, a resposta a esta pergunta é quase ilimitada, ou seja, qualquer coisa que as pessoas façam. Contudo, dada a centralidade da dominação neste modelo, as formas mais significativas de prática são aquelas com implicações políticas intencionais e não intencionais. Novamente, quase tudo o que as pessoas fazem tem tais implicações. Então, o estudo da prática, afinal de contas, é o estudo de todas as formas de ação humana, porém de um ponto de vista particular - um ponto de vista político.

Além deste ponto geral, podem ser introduzidas outras distinções adicionais. Primeiro, existe a questão do que se considera como unidades de ação. A maior parte da antropologia da prática até hoje concebe estas unidades como atores individuais, quer como indivíduos históricos reais, quer como tipos sociais ("mulheres", "plebeus", "trabalhadores", "irmãos mais novos" etc.). O analista toma estas pessoas e seus atos como ponto de referência para entender um desdobramento de eventos específicos e/ou para entender processos envolvidos na reprodução ou na mudança de algum conjunto de características estruturais. Em contraste com um grande corpo de trabalhos no campo da história, na antropologia se tem feito relativamente pouco sobre a ação coletiva concertada (mas ver Wolf 1969; Friedrich 1970; Blu 1980; ver também a literatura sobre os cultos de cargo, principalmente Worsley 1968). Mesmo em estudos sobre ação coletiva, a coletividade é tratada metodologicamente como um sujeito singular. Vamos discutir, nesta seção, alguns dos problemas que surgem do individualismo que, no fundo, caracteriza a maioria das formas atuais da teoria da prática.

Um segundo conjunto de questões tem a ver com a organização temporal da ação. Alguns autores (Bourdieu é um exemplo) tratam a ação em termos de tomada de decisões ad hoc, e/ou em "jogadas" relativamente a curto prazo. Outros sugerem, apesar de não desenvolverem o ponto, que os seres humanos agem conforme planos ou programas, cuja perspectiva temporal é sempre mais longa do que qualquer jogada singular, e que, sem dúvida, a maioria das jogadas é inteligível somente no contexto desses planos mais amplos (Isto está implícito em Sahlins (1981), assim como em Ortner (1981) e Collier \& Rosaldo (1981); para um exemplo mais antigo, ver Hart \& Pilling 1960). Muitos desses planos são providenciados culturalmente (o ciclo normativo de vida, por exemplo), mas muitos outros têm que ser construídos pelos próprios atores. Contudo, até os projetos gerados ("criativamente") pelos atores tendem a assumir formas estereotipadas, na medida em que os recursos e os constrangimentos do sistema são relativamente constantes para atores em posições similares. De qualquer forma, enfatizar "projetos" 
mais amplos ao invés de "jogadas" particulares sublinha o ponto de que a ação em si tem estrutura (em desenvolvimento), ao mesmo tempo em que opera na, e em relação à estrutura.

Finalmente, há a questão dos tipos de ação considerados analiticamente centrais à abordagem atual. Parece que todos concordam em se opor a uma visão parsoniana ou saussuriana, na qual a ação é vista como mera encenação ou execução de regras ou normas (Bourdieu 1978; Sahlins 1981; Giddens 1979). Além do mais, todos parecem concordar também sobre o fato de que um tipo de "voluntarismo" romântico ou heróico, que enfatiza a liberdade e a inventividade relativamente irrestrita dos atores, também não serve (p.ex.,Thompson 1978). O que resta então é uma visão da ação posta, em boa medida, em termos de escolha pragmática e tomada de decisão, e/ou de cálculo ou estratégia ativa. Na próxima seção será dito mais sobre o modelo estratégico, quando discuto as visões da motivação embutidas na teoria da prática. Aqui, no entanto, quero questionar se a crítica da encenação ou execução talvez não tenha ido longe demais. Sem dúvida, apesar dos ataques a Parsons por Bourdieu e Giddens, ambos reconhecem o papel central do comportamento altamente padronizado e rotinizado na reprodução sistêmica. É precisamente nessas esferas da vida - em especial no chamado domínio doméstico - nas quais a ação procede com escassa reflexão, que muito do conservadorismo de um sistema tende a estar localizado. O grau segundo o qual os atores simplesmente encenam normas, pois "era o jeito dos nossos ancestrais", pode estar sendo indevidamente subestimado pelo fato de que os teóricos da prática querem enfatizar a dimensão ativa e intencional da ação; ou por causa de um crescente interesse na mudança mais do que na reprodução; ou por ambos esses motivos.

\section{O que motiva a ação?}

Uma teoria da prática requer algum tipo de teoria da motivação. No momento, a teoria da motivação dominante na antropologia da prática é derivada da teoria do interesse. O modelo é o de um ator essencialmente individualista e de alguma forma agressivo, egoísta, racional, pragmático e talvez também com uma orientação maximizadora. O que os atores fazem, supõe-se, é ir atrás do que eles querem de forma racional; e o que eles querem é material e politicamente útil para eles, no contexto das próprias situações culturais e históricas.

A teoria do interesse já foi muito discutida. Basta aqui notar apenas alguns pontos particularmente relevantes para os estudos antropológicos da prática. 
Na medida em que a teoria do interesse é uma teoria psicológica, embora pretenda não sê-lo, é evidente que ela é estreita demais. Em particular, embora a racionalidade pragmática seja com certeza um aspecto da motivação, ela nunca é a única, e nem sempre é a dominante. Para lhe conferir o status de força motivadora exclusiva, é preciso excluir do discurso analítico toda uma série de termos emocionais - carência, medo, sofrimento, desejo e outros - que decerto fazem parte da motivação.

Infelizmente, em geral os antropólogos têm tido dificuldades metodológicas para abordar atores demasiadamente "psicologizados", e os teóricos da prática não constituem uma exceção. Existe, contudo, um corpus crescente de literatura que explora a construção variável de self, pessoa, emoção e motivo numa perspectiva de comparação intercultural (p.ex., M. Rosaldo 1980, 1981; Friedrich 1977; Geertz 1973a, 1975; Singer 1980; Kirkpatrick 1977; Guemple 1972). O próprio crescimento deste corpus de trabalhos faz parte da tendência mais ampla em direção a um interesse em elaborar um paradigma centrado no ator, na qual pode se incluir o fato do aparente ressurgimento do subcampo da antropologia psicológica (p.ex., Paul 1982; Kracke 1978; Levy 1973). É de se esperar que aconteçam alguns intercâmbios frutíferos entre as abordagens mais sociologicamente orientadas da prática, com as suas visões do motivo relativamente desnaturadas, e algumas destas abordagens da emoção e da motivação tecidas de forma mais rica.

Se a teoria do interesse supõe racionalidade demais da parte dos atores, ela também presume demasiada atividade. A ideia de que os atores estão sempre reivindicando, perseguindo fins, avançando propósitos, e coisas do tipo poderia simplesmente ser uma visão excessivamente dinâmica (e excessivamente política) de como e por que as pessoas agem. Poderíamos aqui nos referir à distinção, sublinhada por Geertz, entre a teoria do interesse e a teoria da tensão (1973c). Se os atores na teoria do interesse estão sempre lutando ativamente para ganhar algo, os atores na teoria da tensão são vistos experimentando as complexidades de suas situações e tentando resolver os problemas postos por aquelas mesmas situações. Decorre destes pontos que a perspectiva da tensão coloca maior ênfase na análise do sistema em si, nas forças em jogo sobre os atores, como forma de entender, diríamos, de onde os atores vêm. Mais especificamente, um sistema é analisado com o objetivo de desvendar os tipos de obrigações que cria para os atores, os tipos de fardos que lhes impõe, e por aí vai. Esta análise, por sua vez, fornece muito do contexto para entender os motivos dos atores e os tipos de projetos que eles constroem para lidar com as próprias situações (ver também Ortner 1975, 1978).

Enquanto a teoria da tensão não retifica as deficiências psicológicas da teoria do interesse, pelo menos ajuda no sentido de oferecer uma inves- 
tigação mais sistemática das forças sociais que moldam os motivos do que aquela proporcionada pela teoria do interesse. Sem dúvida, poderia ser dito que a teoria da tensão é uma teoria da produção "social" dos "interesses", em oposição à sua produção "psicológica", sendo esta última vista menos como expressões diretas da utilidade e da vantagem para os atores, e mais como imagens de soluções para os problemas e as tensões que são experimentados.

Por fim, uma abordagem baseada na noção de interesse tem a tendência de acompanhar uma visão da ação como "jogadas" táticas de curto prazo em vez de "projetos" de desenvolvimento a longo prazo. De um ponto de vista tático, os atores buscam ganhos particulares, enquanto do ponto de vista do desenvolvimento, os atores são vistos como envolvidos em transformações de um alcance relativamente longo dos seus próprios estados de ser - das suas próprias relações com as coisas, com as pessoas e com o self. Poderíamos dizer, com Gramsci, que a ação, numa perspectiva de desenvolvimento ou de "projetos", é mais uma questão de "se tornar" do que de "buscar" (1957). Intrínseco a esta última perspectiva está um sentido de que o motivo e a ação são moldados não só pelos problemas a serem resolvidos e pelos ganhos a serem procurados, mas pelas imagens e os ideais do que constitui o bem - nas pessoas, nas relações e nas condições de vida.

É uma peculiaridade da teoria do interesse que ela seja compartilhada por um amplo espectro de analistas, marxistas, não marxistas, teóricos da prática "antigos" e "novos". A popularidade e a durabilidade da perspectiva e isto apesar de numerosos ataques e críticas - sugerem que, para algo vir a ser modificado nesta área, serão necessárias mudanças especialmente profundas nas nossas próprias práticas.

\section{A natureza das interações entre a prática e o sistema}

1. Como é que o sistema configura a prática? Os antropólogos - ao menos, os norte-americanos - na sua maioria concordaram durante muito tempo que a cultura configura, guia e até certo ponto dirige o comportamento. Nos anos 60, Geertz elaborou alguns dos importantes mecanismos envolvidos nesse processo, e me parece que a maioria dos teóricos da prática modernos, inclusive aqueles que escrevem em termos marxistas e/ou estruturalistas, tem um ponto de vista essencialmente geertziano. Mas existem algumas mudanças de ênfase, derivadas da centralidade da dominação no marco da prática. De um lado, como já foi mencionado, a ênfase tem se deslocado de aquilo que a cultura deixa e permite que as pessoas vejam, sintam e façam 
para aquilo que ela restringe e inibe ver, sentir e fazer. Mais ainda, apesar de se concordar que a cultura constitui a realidade em que os atores vivem de uma maneira poderosa, essa realidade é examinada com olhos críticos: por que esta e não alguma outra? E quais tipos de alternativas as pessoas estão sendo impedidas de ver?

É importante notar que esta visão se distingue, ao menos em parte, de uma visão da cultura como mistificação. Nesta última perspectiva, a cultura (= "ideologia") mente sobre as realidades das vidas das pessoas, e o problema analítico consiste em entender como as pessoas chegam a acreditar nessas mentiras (p.ex., Bloch 1977). No enfoque que estamos discutindo aqui, no entanto, existe somente uma realidade, e ela é constituída culturalmente dos pés à cabeça. O problema não é que o sistema diga mentiras sobre alguma "realidade" extrassistêmica, mas por que o sistema em seu conjunto possui certa configuração, e por que e como ele exclui configurações alternativas possíveis.

De todo modo, em termos da questão específica de como o sistema constrange as práticas, a ênfase tende a ser posta em mecanismos essencialmente culturais e psicológicos: mecanismos da formação e da transformação da "consciência". Apesar de os constrangimentos de tipo material e político, incluindo a força, serem plenamente tomados em consideração, parece haver um acordo geral sobre a ação: que ela é constrangida mais profunda e sistematicamente pelas maneiras com que a cultura controla as definições de mundo dos atores, limita suas ferramentas conceituais e restringe seus repertórios emocionais. A cultura vira parte do self. Falando sobre o senso de honra entre os Kabile, por exemplo, Bourdieu diz:

[...] a honra é uma disposição permanente, enraizada nos próprios corpos dos agentes em forma de disposições mentais, esquemas de percepção e pensamento, extremamente gerais em sua aplicação, tais como aquelas que dividem o mundo de acordo com as oposições entre masculino e feminino, leste e oeste, futuro e passado, acima e abaixo, direita e esquerda etc., e também, num nível mais profundo, na forma de posturas e atitudes corporais, modos de estar em pé, sentar, olhar, falar ou andar. O que é chamado o senso de honra não é mais do que a disposição cultivada, inscrita no esquema corporal e nos esquemas de pensamento (1978:15).

De maneira semelhante, Foucault diz sobre o discurso das "perversões":

A mecânica do poder que ardorosamente persegue todo esse despropósito só pretende suprimi-lo atribuindo-lhe uma realidade analítica visível e permanente: encrava-o nos corpos, o introduz nas condutas, torna-o princípio de classificação 
e de inteligibilidade e o constitui em razão de ser e ordem natural da desordem [...] Trata-se, através de sua disseminação, de semeá-las no real e de incorporálas ao indivíduo (1980:44).*

Desta forma, na medida em que a dominação é tanto questão de processos culturais e psicológicos como de processos materiais e políticos, ela opera conformando as disposições dos atores de modo que, em última instância, "as aspirações dos agentes têm os mesmos limites que as condições objetivas das quais elas são o produto" (Bourdieu 1978:166; ver também Rabinow 1975; Barnett \& Silverman 1979; Rabinow \& Sullivan 1979).

Ao mesmo tempo, no entanto, aqueles autores que enfatizam a dominação cultural também colocam limites importantes sobre o escopo e a profundidade dos controles culturais. O caso extremo nunca é alcançado, e frequentemente nem mesmo aproximado. Assim, enquanto aceitam a visão da cultura como poderosamente constrangedora, eles argumentam que a hegemonia sempre é mais frágil do que parece, e nunca tão total como ela (ou como a antropologia cultural tradicional) reivindicaria. As razões que se alegam para este estado de coisas são variadas, e estão relacionadas diretamente às maneiras com que os diferentes autores concebem a mudança sistêmica. Isto nos leva para nosso último conjunto de questões.

2. Como a prática modela o sistema? Na verdade, aqui estão presentes duas considerações: como a prática reproduz o sistema, e como o sistema pode ser mudado pela prática. Idealmente, uma teoria da prática que é unificada daria conta de ambas em um mesmo marco. Até agora, contudo, está claro que um foco na reprodução tende a produzir um quadro bastante diferente do que um foco na mudança; portanto, trataremos esses assuntos separadamente.

Começando com a reprodução, existe, é claro, uma longa tradição na antropologia em perguntar como é que as normas, os valores e os esquemas conceituais vêm a ser reproduzidos por e para os atores. Antes dos anos 60, ao menos na antropologia norte-americana, a ênfase era colocada nas práticas de socialização como agente principal desse processo. Na Inglaterra, não obstante, a influência do paradigma durkheimiano gerou uma ênfase no ritual. Era através da participação em rituais de vários tipos que os atores eram vistos apegando-se às normas e aos valores da sua cultura e/ou livrando-se, ao menos temporariamente, de quaisquer sentimentos dissidentes que pudessem abrigar (p.ex., Gluckman 1955; V. Turner 1969; Beidelman 1966). O foco no

* [N.T.] Tradução para o português: História da Sexualidade I. A vontade de saber. 1999. Tradução de Maria Thereza da Costa Albuquerque e J. A. Guilhoa Albuquerque. Rio de Janeiro: Graal. 
ritual, ou o que poderíamos denominar o foco numa prática extraordinária, tornou-se ainda mais forte nos anos 60 e 70. Os antropólogos simbólicos norte-americanos adotaram a perspectiva de que o ritual era uma das matrizes principais para a reprodução da consciência (Geertz 1973b; Ortner 1978), mesmo que discordassem de certos aspectos da abordagem britânica. E os marxistas estruturais também atribuíram grande peso ao poder do ritual para mediar as contradições sociais estruturais e mistificar a operação do sistema. O ritual, de fato, é uma forma de prática — as pessoas o praticam - e estudar a reprodução da consciência, mistificada ou não, no processo da conduta ritual é estudar ao menos uma maneira em que a prática reproduz o sistema.

Enfoques mais novos sobre a prática, em contraste, colocam maior ênfase nas práticas da vida cotidiana. Embora não sejam de modo algum ignoradas nos trabalhos anteriores, elas assumem maior preeminência aqui. Assim, apesar de sua ênfase nos momentos da prática altamente intencionais, Bourdieu também presta atenção de perto nas pequenas rotinas que as pessoas realizam repetidamente ao trabalhar, comer, dormir e relaxar, assim como nas pequenas encenações da etiqueta que praticam uma e outra vez na interação social. Todas essas rotinas e encenações se baseiam e incorporam em si as noções fundamentais do ordenamento temporal, espacial e social que subjazem e organizam o sistema como um todo. Ao performatizar essas rotinas, os atores não só continuam a ser formados pelos princípios organizacionais envolvidos, como voltam a endossar continuamente esses princípios no mundo da observação e do discurso públicos.

Uma questão que se oculta por trás de tudo isto é se de fato toda prática, todas as coisas que todo mundo faz, incorpora e, portanto, reproduz os pressupostos do sistema. Efetivamente, há um profundo tema filosófico aqui: como, se os atores são seres totalmente culturais, poderiam fazer alguma coisa que não carregasse consigo pressuposições culturais centrais? Num plano mais mundano, levanta-se a questão de se as práticas divergentes ou não normativas são simplesmente variações sobre temas culturais básicos, ou se de fato implicam modos alternativos de ser social e cultural.

Estas duas formulações estão baseadas em dois modelos bem diferentes de mudança sistêmica. Um é o modelo marxista clássico, em que as divisões do trabalho e as assimetrias das relações políticas criam, de fato, contraculturas incipientes dentro do sistema dominante. Ao menos algumas das práticas e dos modos de consciência dos grupos dominados "escapam" à hegemonia prevalecente. A mudança acontece como resultado da luta de classes, na qual grupos anteriormente dominados assumem o poder e instituem uma nova hegemonia baseada nas suas próprias maneiras de ver e organizar o mundo. 
Há uma série de problemas com este modelo que não discutirei aqui. Simplesmente mencionarei que ele parece exagerar as diferenças de orientações conceituais, em vez de táticas, entre classes ou outras entidades relacionadas assimetricamente. O modelo parece funcionar melhor quando as diferenças de classe são também, historicamente, diferenças culturais, como nos casos do colonialismo e o imperialismo (p.ex., Taussig 1980). Não funciona tão bem nos muitos outros tipos de casos com que os antropólogos lidam tipicamente - sistemas culturalmente homogêneos nos quais as iniquidades e assimetrias de vários tipos (baseadas em gênero, idade ou parentesco, por exemplo) são inseparáveis de complementaridades ou reciprocidades que são igualmente reais e vividas de modo igualmente forte.

Recentemente, Sahlins apresentou um modelo que origina a mudança sistêmica nas práticas de uma maneira bastante diferente. Sahlins argumenta que a mudança radical não precisa ser equiparada com a chegada ao poder de grupos com visões de mundo alternativas. Ele enfatiza, em lugar disto, a importância das mudanças de significado das relações existentes.

Resumidamente, Sahlins argumenta que as pessoas em diferentes posições sociais têm diferentes "interesses" (um termo sobre o qual Sahlins remói e que utiliza em um sentido estendido), e agem em conformidade com esses interesses. Em si isto não implica conflito ou luta, nem mesmo implica que pessoas com interesses diversos tenham visões de mundo radicalmente distintas. Contudo, implica que, ao surgirem oportunidades, elas procurarão reforçar as suas posições, mas que irão fazê-lo pelos meios tradicionalmente disponíveis para pessoas em suas posições. A mudança ocorre quando as estratégias tradicionais, que tomam como dados os padrões de relações tradicionais (por exemplo, entre chefes e plebeus, ou entre homens e mulheres), desdobram-se em relação a novos fenômenos (por exemplo, a chegada do Capitão Cook no Havaí) que não respondem a essas estratégias de maneiras tradicionais. Esta mudança de contexto, esse caráter refratário do mundo real às expectativas tradicionais põem em causa tanto as estratégias da prática quanto a natureza das relações que elas pressupunham:

[...] a pragmática tinha sua própria dinâmica: relacionamentos que não permitiram a realização das intenções nem o desenrolar da convenção. O complexo de trocas que se desenvolveu entre havaianos e europeus [...] levou os primeiros a condições de conflito interno e de contradição atípicas. Por essa via suas conexões diferenciadas com os europeus conferiram novos conteúdos funcionais às relações entre eles mesmos. Isto é transformação estrutural. Os valores adquiridos na prática retornam à estrutura na forma de novas relações entre suas categorias (Sahlins 1981:50). 
O modelo de Sahlins é atraente em diversos sentidos. Como já mencionado, ele não equipara a divergência de interesse com uma formação quase que contracultural e, como consequência, não se vê forçado a enxergar a mudança em termos da substituição real dos grupos (embora no final das contas isto aconteça, no caso havaiano também). Além disso, ao argumentar que a mudança pode vir a acontecer em grande parte por meio de tentativas malsucedidas de aplicar interpretações e práticas tradicionais, seu modelo conjuga mecanismos de reprodução e transformação. Mudança, como ele afirma, é reprodução fracassada. E, finalmente, ao ressaltar que as mudanças de significado são um processo essencialmente revolucionário, ele confere à própria revolução um status menos extraordinário (se não menos dramático, à sua maneira) do que defenderiam os modelos-padrão.

Pode-se, entretanto, registrar algumas questões. Sahlins ainda está lutando com a perspectiva do interesse. Ele confronta isto de forma breve e oferece uma fórmula que tenta suavizar algumas de suas qualidades mais etnocêntricas, mas não lida de forma resolutiva com a gama completa de pensamentos e sentimentos que motivam os atores a agir, e a agir de maneiras complexas.

Além disso, pode-se sugerir que Sahlins faz com que a mudança pareça um pouco fácil demais. Claro que o livro é curto, e o modelo apenas esboçado. Ademais, a "abertura" relativa de um determinado sistema, e de diferentes tipos de sistemas, provavelmente é empiricamente variável (ver, p.ex., Yengoyan 1979). Não obstante, Sahlins menciona apenas de passagem os vários mecanismos que tendem, no curso normal dos acontecimentos, a manter o sistema em seu devido lugar, apesar de parecerem ser mudanças importantes nas práticas. As jogadas para manter o status quo por parte daqueles que têm direitos adquiridos talvez se encontrem entre os menos importantes; em qualquer caso, elas podem sair pela culatra ou produzir resultados novos inesperados. De maior importância aqui é o entrave introduzido no sistema pelo fato de que, como resultado da enculturação, os atores encarnam o sistema, assim como vivem dentro dele (ver Bourdieu 1978). Mas os atores maduros não são tão flexíveis assim. Para se ter um modelo adequado da capacidade que a prática tem para revisar a estrutura, este deveria compreender, provavelmente, um esquema de desenvolvimento de longo prazo, de duas ou três gerações.

Um ponto relacionado deriva do fato de que grande parte da reprodução sistêmica ocorre por meio de atividades rotineiras e de interações íntimas da vida doméstica. Na medida em que a vida doméstica é isolada da esfera social mais ampla (geralmente num grau muito maior do que é o caso na Polinésia), importantes práticas - de relações de gênero e de socialização 
de crianças - permanecem relativamente intocadas, e a transmissão de novos significados, valores e relações categoriais às gerações futuras pode ser impedida. No mínimo, o que é transmitido será modificado significativamente - e de modo conservador.

Em suma, provavelmente, há muito mais conexões e muito mais possibilidades de tropeços na rota que leva da prática de volta à estrutura do que o relato relativamente fluido de Sahlins permite. No entanto, se o curso da mudança estrutural é mais difícil do que ele faz parecer, Sahlins apresenta um argumento convincente de como ela pode ser mais fácil do que alguns afirmariam.

Termino esta seção final chamando a atenção para duas ressalvas além das já manifestadas. A primeira diz respeito à centralidade da dominação dentro do quadro contemporâneo da teoria da prática, ou pelo menos dentro do segmento desta abordada aqui. Estou convencida, como muitos dos autores, de que penetrar no funcionamento das relações sociais assimétricas é penetrar no coração de muito do que está acontecendo em um determinado sistema. Estou igualmente convencida, no entanto, de que tal empreendimento, tomado por si só, é unilateral. Padrões de cooperação, reciprocidade e solidariedade constituem o outro lado da moeda do ser social. Neste contexto pós-década de 70, visões do social em termos de partilha, troca e obrigação moral - na famosa frase de David Schneider, "solidariedade difusa e duradoura" - são tratadas principalmente como ideologia. Claro, de fato frequentemente são ideológicas. No entanto, uma visão hobbesiana da vida social é certamente tão tendenciosa como uma que remeta a Rousseau. Um modelo adequado deve englobar o conjunto completo.

Meu segundo ponto não é tanto uma ressalva crítica, mas aponta para uma ironia no cerne do modelo da prática. A ironia, embora alguns talvez não a percebam como tal, é esta: que, embora se confira às intenções dos atores um lugar central no modelo, geralmente mudanças sociais importantes não acontecem como consequência intencional da ação. A mudança é em grande medida um subproduto, uma consequência não intencional da ação, por mais racional que a ação tenha sido. Ao procurarem conceber crianças com mana superior deitando com os marinheiros britânicos, as mulheres havaianas tornaram-se agentes do espírito do capitalismo em sua sociedade. Ao procurarem preservar a estrutura e diminuir a anomalia matando um "deus" que de fato era o Capitão Cook, os havaianos colocaram em movimento um comboio de eventos que finalmente derrubou os seus deuses, seus chefes, e o mundo tal como o conheciam. Dizer que a sociedade e a história são produtos da ação humana é verdade, mas apenas se entendido em um sentido algo irônico. Elas raramente são os produtos que os atores intencionam criar. $^{19}$ 


\section{Conclusões e perspectivas para o futuro}

Não tem sido minha intenção, como disse anteriormente, fazer um relato exaustivo de nenhuma escola de pensamento antropológico das últimas duas décadas. Antes, apontei para as relações entre várias tendências intelectuais do campo, no tempo e através dele. Esta tampouco tem sido uma investigação totalmente desinteressada, o que sem dúvida é óbvio. As correntes de pensamento que escolhi enfatizar são aquelas que eu vejo como as mais importantes no processo de trazer o campo até certa posição atual, e minhas representações sobre onde nós estamos hoje são elas próprias claramente seletivas.

Muito do que foi dito neste ensaio pode ser subsumido no pequeno epigrama de Peter Berger e Thomas Luckmann: "A sociedade é um produto humano. A sociedade é uma realidade objetiva. O homem é um produto social" (1967:61). A maioria das antropologias precedentes tem enfatizado o segundo componente desse conjunto: a sociedade (ou a cultura) foi vista como uma realidade objetiva de uma forma ou de outra, com sua própria dinâmica em boa parte divorciada da agência humana. Os antropólogos culturais e psicoculturais norte-americanos, além disso, enfatizaram o terceiro componente, as maneiras com que a sociedade e a cultura dão forma à personalidade, à consciência, aos modos de ver e sentir. Mas até pouco tempo atrás, poucos esforços haviam se dedicado a entender como a sociedade e a cultura, elas mesmas, são produzidas e reproduzidas pela intenção e a ação humanas. É em torno desta questão, a meu ver, que a antropologia dos anos 80 começa a tomar forma, enquanto, ao mesmo tempo, mantém - idealmente um sentido das verdades das duas outras perspectivas.

Desta forma, tomei a prática como o símbolo-chave da antropologia dos anos 80. Estou consciente, no entanto, de que muitos teriam escolhido um símbolo diferente: a história. Em torno deste termo agrupam-se noções de tempo, processo, duração, reprodução, mudança, desenvolvimento, evolução, transformação (ver Cohn 1981). Assim, em lugar de ver o deslocamento teórico no campo como um movimento das estruturas e dos sistemas para as pessoas e as práticas, ele poderia ser visto como um deslocamento das análises estáticas e sincrônicas para as análises diacrônicas e processuais. Ao ver o deslocamento desta maneira, o enfoque da prática compreende somente uma ala do movimento em direção à diacronia, por enfatizar processos de microdesenvolvimento: transações, projetos, carreiras, ciclos de desenvolvimento e similares.

A outra ala do movimento em direção à diacronia é macroprocessual ou macro-histórica, e compreende ao menos duas tendências. De um lado, está a escola da economia política já discutida, que tenta entender a mudança 
nas sociedades de pequena escala tradicionalmente estudadas pelos antropólogos que relacionaram essa mudança aos desenvolvimentos históricos de larga escala (especialmente o colonialismo e a expansão capitalista) externos às sociedades em questão. Do outro, há uma forma de investigação histórica de um tipo mais etnográfico, que presta mais atenção às dinâmicas de desenvolvimento internas de sociedades particulares ao longo do tempo. Influências externas são tomadas em consideração, mas há um esforço maior em delinear as forças que trabalham tanto para a estabilidade como para a mudança dentro de um sistema determinado, assim como os filtros sociais e culturais que operam para selecionar e/ou reinterpretar o que for que esteja entrando a partir do exterior (p.ex., Geertz 1980b; Blu 1980; R. Rosaldo 1980; Wallace 1980; Sahlins 1981; Kelly 1985; Ortner 1989).

A reaproximação da antropologia com a história é, do meu ponto de vista, um desenvolvimento extremamente importante para o campo como um todo. Se eu escolhi não enfatizá-la neste ensaio é somente porque, por enquanto, a tendência é muito ampla. Ela cobre, mais do que revela, distinções importantes. Na medida em que a história está sendo amalgamada com virtualmente qualquer tipo de trabalho antropológico, ela oferece uma pseudo integração do campo que não consegue abordar alguns dos problemas mais profundos. Como afirmei neste ensaio, esses problemas mais profundos foram gerados pelos próprios sucessos das abordagens estruturalistas e sistêmicas, que estabeleceram a realidade da natureza coisificada da sociedade, mas falharam em não perguntar, de um modo sistemático, de onde a coisa vem e como ela poderia mudar.

Responder a estas questões com a palavra "história" é evitá-las, se por história se entende uma cadeia de eventos externos aos quais as pessoas reagem. A história não é simplesmente algo que acontece às pessoas, mas algo que elas fazem - dentro, claro, dos limites muito poderosos impostos pelo sistema em que estão operando. Uma abordagem a partir da prática tenta ver esse fazer, seja no passado ou no presente, seja na criação de novidade ou na reprodução das mesmas coisas de sempre. Mais do que "fetichizar" a história, o enfoque da prática oferece, ou ao menos promete, um modelo que implicitamente unifica estudos históricos e antropológicos. ${ }^{20}$

Naturalmente, já houve tentativas anteriores de trazer a agência humana de volta para o quadro. Essas tentativas, contudo, cederam ora demasiado, ora muito pouco à perspectiva sistêmico/estrutural. No caso da "teoria geral da ação" de Parsons, a ação era vista quase puramente como colocar em ação regras e papéis do sistema. No caso do interacionismo simbólico e do transacionalismo, os constrangimentos sistêmicos foram minimizados, sendo o próprio sistema visto como um reservatório relativamente desordenado de 
"recursos" que os atores utilizam para construir suas estratégias. As versões modernas da teoria da prática, de outro lado, parecem únicas em aceitar os três lados do triângulo de Berger e Luckmann: que a sociedade é um sistema, que o sistema é poderosamente constrangedor, e mesmo assim que o sistema pode ser feito e desfeito por meio da ação e da interação humanas.

O que não quer dizer que a perspectiva da prática representa o fim da dialética intelectual, nem que é perfeita. Apontei para muitos de seus defeitos neste ensaio. Como qualquer teoria, é um produto do seu tempo. Alguma vez a prática teve a aura romântica do voluntarismo: "o homem", dizia-se, "se faz a si mesmo". Agora a prática possui qualidades relacionadas com os duros tempos atuais: pragmatismo, maximização de benefícios; "cada um", diz o ditado, "é por si". Tal perspectiva parece natural no contexto do fracasso de muitos dos movimentos sociais dos anos 60 e 70, e no contexto de uma economia desastrosa e de uma ameaça nuclear aquecida. Mas por mais realista que pareça agora, essa perspectiva é tão enviesada como o próprio voluntarismo. Muito trabalho resta a ser feito.

Cecilia McCallum é professora do Departamento e da Pós-Graduação em Antropologia da UFBA. E-mail: < cecilia.mccallum@uol.com.br>

Clara Lourido é doutoranda em antropologia na UFBA. E-mail: < clara.lourido. ufba@gmail.com>

Samuel Lira Gordenstein é doutorando em antropologia na UFBA. E-mail: <samgordenstein@hotmail.com>

\section{Notas}

1 Tradução de "Theory in Anthropology since the Sixties", originalmente publicado em Comparative Studies in Society and History, 26(1):126-166, jan. 1984. Tradução de Cecilia McCallum, Clara Lourido e Samuel Lira Gordenstein, que teve sua origem em um esforço conjunto de alguns dos alunos do Programa de Pós-Graduação em Antropologia da Universidade Federal da Bahia, na disciplina "Seminários Avançados em Teoria Antropológica", sob a coordenação e com a revisão de Cecilia McCallum, no semestre 2010.1. Agradecemos a Ângela Elisabeth Weber, Arydimar V. Gaioso, Brazão José Luis Catopola, Davi Pereira Junior, Franklin P. de Carvalho, Helen Catalina Ubinger, Isabele Costa Duplat, Lorena Volpini, Maria Cristina Santos Pechine e Rosana Carvalho de Paiva. 
${ }^{2}$ Para a discussão sobre os anos 60 e 70, eu irei mencionar apenas as figuras e os trabalhos mais representativos. Em um artigo deste tamanho, muitos desenvolvimentos interessantes devem ser deixados de lado. Uma figura importante desse período, que é colocada à margem, é Gregory Bateson (p.ex. 1972) que, apesar de ser claramente um pensador poderoso e original, nunca chegou a fundar realmente uma escola importante na antropologia.

${ }^{3}$ P. ex., Ortner 1975; M. Rosaldo 1980; Blu 1980; Meeker 1979; Rosen 1978.

${ }^{4}$ Se a própria cultura tem sido um fenômeno indefinível, pode-se dizer que Geertz tem se dedicado à parte mais inalcançável da cultura, o ethos. Pode-se sugerir também que isto, entre outras coisas, explica sua ampla e duradoura popularidade. Talvez a maioria dos estudantes que entram na antropologia e quase certamente a maioria dos não antropólogos que são fascinados por nosso campo são atraídos porque, em algum momento de sua experiência, eles já se defrontaram com a "alteridade" de outra cultura, o que nós chamaríamos seu ethos. O trabalho de Geertz proporciona uma das pouquíssimas chaves para entender essa alteridade.

${ }^{5}$ Outro ponto de contraste entre Turner e Geertz é que o conceito de significado de Turner é principalmente referencial, ao menos naqueles seus trabalhos iniciais que lançaram sua abordagem. Significados são coisas para as quais os símbolos apontam ou se referem, como "matrilinhagem", ou "sangue". Geertz, por outro lado, está primordialmente preocupado com o que pode ser chamado Significado, com S maiúsculo - o propósito, ou objetivo, ou o significado mais abrangente das coisas. Deste modo, ele cita Northrop Frye: "Você não consultaria Macbeth para aprender sobre a história da Escócia - consulta-o para aprender como o homem se sente depois de ter ganhado seu reino e perdido sua alma" (Geertz 1973f:450).

${ }^{6}$ Por exemplo, Munn 1969; Myerhoff 1974; Moore \& Myerhoff 1975; Babcock 1978.

${ }^{7}$ Esta seção se baseia parcialmente em leituras, parcialmente em entrevistas semiformais com Conrad P. Kottak e Roy A. Rappaport, e parcialmente em discussões gerais com Raymond C. Kelly. Nenhum informante é responsável pelo resultado final.

${ }^{8}$ White e Childe deixaram bastante clara a influência marxista em seu trabalho.

${ }^{9}$ Esta era a posição programática. Na prática, Sahlins prestou bastante atenção nas dinâmicas sociais internas.

${ }^{10}$ Turner, nos seus primeiros trabalhos, é uma exceção parcial a este ponto, mas a maioria de seus sucessores não.

${ }^{11}$ Dumont é outra dessas figuras que merecem mais espaço do que pode ser dado aqui.

12 Isto não implica que os antropólogos simbólicos norte-americanos neguem a doutrina da arbitrariedade dos símbolos. Mas eles insistem em que a escolha de 
uma forma simbólica particular dentre vários símbolos possíveis, igualmente arbitrários, para a mesma concepção, não somente não é arbitrária como tem importantes implicações que devem ser investigadas.

${ }^{13}$ James Boon (p.ex., 1972) dedicou um esforço considerável para reconciliar Lévi-Strauss e/ou Schneider, de um lado, com Geertz, de outro. O resultado geralmente pende para o estruturalismo (ver também Boon \& Schneider 1974).

${ }^{14}$ O próprio Lévi-Strauss se deslocou de uma postura durkheimiana/maussiana em "A gesta de Asdiwal" (1967) para a postura mais radicalmente estruturalista nas Mitológicas. Não é por acaso que Leach, ou quem quer que seja que tenha tomado a decisão, escolheu apresentar "A gesta de Asdiwal" como o primeiro ensaio da coletânea britânica $O$ estudo estrutural do mito e o totemismo (1967).

${ }^{15}$ É possível remontar à tradição transacionalista na antropologia britânica em épocas anteriores, com Barth e Bailey nos anos 1960, entre as primeiras publicações de Leach (p.ex., 1960), e levando originalmente a Raymond Firth (p.ex., 1963 [1951]). Ver também Marriott (1976) nos Estados Unidos.

${ }^{16}$ Se eu tivesse mais espaço, apresentaria o argumento de que a antropologia feminista é um dos principais contextos em que a abordagem da prática se desenvolveu. O artigo de Collier e Rosaldo (1981) é um belo exemplo. Ver também Ortner (1981).

${ }^{17}$ Mayer Zald, comunicação pessoal, no Seminário de História das Ciências Sociais (University of Michigan, 1982).

${ }^{18}$ Parsons e seus colegas atribuíam ao termo "ação" um lugar central no seu esquema (1962 [1951]), mas com isto queriam dizer, essencialmente, pôr em prática regras e normas. Bourdieu, Giddens e outros têm sinalizado isto ao construírem os seus argumentos parcialmente contra essa posição.

${ }^{19}$ Michel Foucault, cuja obra mais tardia (1979 e 1980) certamente faz parte da tendência de prática atual, e que está fazendo um impacto em pelo menos alguns setores da antropologia, tem colocado bem este ponto: "As pessoas sabem o que fazem, elas frequentemente sabem porque fazem o que fazem, mas o que elas não sabem é o que o que elas fazem faz" (citado em Dreyfus \& Rabinow 1982:187). Lamento ter sido incapaz de incorporar Foucault nas discussões desta seção. Em particular, ele vem lutando contra algumas das ramificações do individualismo no coração de muita teoria da prática, embora no processo ele tenha acabado por se enredar em outros nós - como na "intencionalidade sem sujeito, [e] uma estratégia sem estrategista" (ibid.).

${ }^{20}$ Pode-se protestar que os antropólogos da economia política põem a prática numa posição central no seu modelo. Quando os eventos externos interferem, os atores numa dada sociedade reagem e tentam lidar com aquelas interferências. O problema aqui é que a ação é primariamente reação. O leitor poderia protestar por sua vez que a reação é central no modelo de Sahlins também. Mas o ponto de Sahlins é que a natureza da reação é conformada tanto pela dinâmica interna como pela natureza dos eventos externos. 


\section{Referências bibliográficas}

ALLAND, Alex. 1975. "Adaptation". Annual Review of Anthropology, 4. Palo Alto: Annual Reviews Inc.

ALTHUSSER, Louis. 1971. Lenin and philosophy. Ben Brewster, trad. New York and London: Monthly Review Press.

AMERICAN ETHNOLOGIST. 1978. Special issue on political economy, 5(3).

ASAD, Talal (org.). 1973. Anthropology and the colonial encounter. London: Ithaca Press.

AVINERI, Shlomo. 1971. The social and political thought of Karl Marx. Cambridge: Cambridge University Press.

BABCOCK, Barbara, (org.). 1978. The reversible world: symbolic inversion in art and society. Ithaca, New York: Cornell University Press.

BAILEY, F. G. 1969. Strategems and spoils. New York: Schocken.

BARNES, J. A. 1980. "Kinship studies: some impressions on the current state of play". Man, 15(2):293-303.

BARNETT, Steve. 1977. "Identity choice and caste ideology". In: J. Dolgin, D. Kemnitzer \& D. Schneider (orgs.), Symbolic anthropology. New York: Columbia University Press.

BARNETT, Steve \& SILVERMAN, Martin G. 1979. Ideology and everyday life. Ann Arbor: University of Michigan Press.

BARTH, Fredrik. 1966. "Models of social organization". Royal Anthropological Institute of Great Britain and Ireland, Occasional Papers, 23.

BATESON, Gregory. 1972. Steps to an ecology of mind. New York: Ballantine Books.

BAUMAN, Richard \& SHERZER, Joel (orgs.). 1974. Explorations in the ethnography of speaking. Cambridge: Cambridge University Press.
BAUMAN, Zygmunt. 1973. Culture as praxis. London and Boston: Routledge and Kegan Paul.

BECKER, A.L. 1979. "Text-building, epistemology, and aesthetics in javanese shadow theater". In: __. \& A. A. Yengoyan (orgs.), The imagination of reality. Norwood, New Jersey: Ablex.

BEIDELMAN, Thomas. 1966. "Swazi royal ritual". Africa, 36(4):373-405.

BERGER, Peter \& LUCKMANN, Thomas. 1967. The social construction of reality. Garden City, New York: Doubleday.

BERREMAN, Gerald. 1962. Behind many masks: ethnography and impression management in a himalayan village. Monograph 4. Ithaca, New York: Society for Applied Anthropology.

BLOCH, Maurice. 1971. "The moral and tactical meaning of kinship terms". Man, 6(1):79-87.

. 1974. "The long term and the short term: the economic and political significance of the morality of kinship". In: J. Goody (org.), The character of kinship. Cambridge: Cambridge University Press. . 1977. "The disconnection between power and rank as a process". Archives Européene de Sociologie, 18:107-48.

BLU, Karen. 1980. The lumbee problem: the making of an american indian people. Cambridge: Cambridge University Press.

BLUMER, Herbert. 1962. "Society as symbolic interaction". In: A. M. Rose (org.), Human behavior and social processes. Boston: Houghton Mifflin.

BOON, James A. 1972. "Further operations of 'culture' in anthropology: a synthesis of and for debate". Social Science Quarterly, 52:221-52.

BOON, James A. \& SCHNEIDER, David M. 1974. "Kinship vis-a-vis myth: 
contrasts in Levi-Strauss' approach to cross-cultural comparison". American Anthropologist, 76(4):794-817.

BOURDIEU, Pierre. 1978 [1972]. Outline of a theory of practice. Richard Nice, trad. Cambridge: Cambridge University Press.

BRADBURY, Malcolm. 1981. Comment on "Modern Literary Theory: its place in teaching". Times Literary Supplement, 137.

CHILDE, V. Gordon. 1942. What happened in history. New York: Penguin.

COHN, Bernard S. 1981. "Anthropology and history in the 1980's". Journal of Interdisciplinary History, 12(2):227-52.

COLE, P. \& MORGAN, J. (orgs.). 1975. Syntax and semantics 3: speech acts. New York: Academic Press.

COLLIER, Jane \& ROSALDO, Michelle Z. 1981. "Politics and gender in simple societies". In: Sherry B. Ortner \& Harriet Whitehead (orgs.), Sexual meanings: the cultural construction of gender and sexuality. Cambridge and New York: Cambridge University Press.

CRAPANZANO, Vincent. 1980. Tuhami: portrait of a moroccan. Chicago: University of Chicago Press.

DEGEORGE, Richard \& DEGEORGE, Fernande (orgs.). 1972. The structuralists from Marx to Lévi-Strauss. Garden City, New York: Doubleday.

DIAMOND, Stanley (ed.). 1979. Toward a marxist anthropology. The Hague: Mouton.

DOLGIN, J.; KEMNITZER, D. \& SCHNEIDER, D. M. 1977. "As people express their lives, so they are...". In: Symbolic anthropology. New York: Columbia University Press.

DOUGLAS, Mary. 1966. Purity and danger. New York: Frederick A. Praeger.

DREYFUS, Hubert L. \& RABINOW, Paul. 1982. Michel Foucault: beyond structuralism and hermeneutics. Chicago: University of Chicago Press.
DUMONT, Louis. 1965. "The modern conception of the individual: notes on its genesis". Contributions to Indian Sociology, 8(1):13-61. . 1970. Homo hierarchicus: an essay on the caste system. M. Sainsbury, trad. Chicago: University of Chicago Press.

FERNANDEZ, James. 1974. "The mission of metaphor in expressive culture". Current Anthropology, 15(2):119-45.

FIRTH, Raymond. 1963 [1951]. Elements of social organization. Boston: Beacon Press.

FOUCAULT, Michel. 1979. Discipline and punish: the birth of the prison. Alan Sheridan, trad. New York: Random House. . 1980. The history of sexuality. Vol. I. Robert Hurley, trad. New York: Vintage.

FRIEDMAN, Jonathan. 1974. "Marxism, structuralism, and vulgar materialism". Man, 9(3):444-69. . 1975. "Tribes, states and transformations". In: M. Bloch (org.), Marxist analyses and social anthropology. New York: John Wiley and Sons.

FRIEDRICH, Paul. 1970. Agrarian revolt in a mexican village. Englewood Cliffs, New Jersey: Prentice-Hall. . 1977. "Sanity and the myth of honor: the problem of Achilles". Ethos, 5(3):281-305.

GEERTZ, Clifford. 1973. The interpretation of cultures. New York: Basic Books. . 1973a. "Thick description: toward an interpretive theory of culture". In: Interpretation of cultures. New York: Basic Books. . 1973b. "Religion as a cultural system". In: Interpretation of cultures. New York: Basic Books.

. 1973c. "Ideology as a cultural system". In: Interpretation of cultures. New York: Basic Books. . 1973d. "The cerebral savage: on the work of Claude Levi-Strauss". In: Interpretation of cultures. New York: Basic Books. 
. 1973e. "Person, time and conduct in Bali". In: Interpretation of cultures. New York: Basic Books.

. 1973f. "Deep play: notes on the balinese cockfight". In: Interpretation of cultures. New York: Basic Books.

. 1975. "On the nature of anthropological understanding". American Scientist, 63(1):47-53.

. 1980a. "Blurred genres: the refiguration of social thought". The American Scholar, 49(2):165-79.

. 1980b. Negara: the theater-state in nineteenth century Bali. Princeton: Princeton University Press.

GENOVESE, Eugene D. 1976. Roll, Jordan, Roll: the world the slaves made. New York: Random House.

GIDDENS, Anthony. 1971. Capitalism and modern social theory. Cambridge: Cambridge University Press.

. 1979. Central problems in social theory: action, structure and contradiction in social analysis. Cambridge: Cambridge University Press.

GLUCKMAN, Max. 1955. Custom and conflict in Africa. Glencoe, Illinois: The Free Press.

GODELIER, Maurice. 1977. Perspectives in marxist anthropology. Robert Brain, trad. Cambridge: Cambridge University Press.

GOFFMAN, Erving. 1959. The presentation of self in everyday life. Garden City, New York: Doubleday.

GOLDMAN, Irving. 1970. Ancient polynesian society. Chicago: University of Chicago Press.

GOLDMANN, Lucien. 1977. Cultural creation in modern society. Bart Grahl, trad. Oxford: Basil Blackwell.

GOODY, Esther N. (org.). 1978. Questions and politeness: strategies in social interaction. New York: Cambridge University Press.

GRAMSCI, Antonio. 1957. The modern prince and other writings. Louis Ma- rks, trad. New York: International Publishers.

GREGOR, Thomas. 1977. Mehinaku: the drama of daily life in a brazilian indian village. Chicago: University of Chicago Press.

GUEMPLE, Lee. 1972. "Panel on cultural basis of social relations: kinship, person, and actor". Annual Meetings of the American Anthropological Association, Toronto, Canadá. Ms.

GUNDER FRANK, Andre. 1967. Capitalism and underdevelopment in Latin America. New York and London: Monthly Review Press.

HABERMAS, Jürgen. 1973. Theory and practice. John Viertel, trad. Boston: Beacon Press.

HARRIS, Marvin. 1966. "The cultural ecology of India's sacred cattle". Current Anthropology, 7(1):51-64. . 1968. The rise of anthropological theory. New York: Crowell. . 1978. "No end of Messiahs". New York Times, 4(21):26, novembro.

HART, Keith. 1982. The development of commercial agriculture in West Africa. Cambridge: Cambridge University Press.

HART, C. W. M. \& PILLING, Arnold R. 1960. The Tiwi of North Australia. New York: Holt, Rinehart, Winston.

HYMES, Dell (org.). 1974. Reinventing anthropology. New York: Vintage.

KAHN, Joel S. 1980. Minangkabau social formations: indonesian peasants and the world economy. Cambridge: Cambridge University Press.

KAPFERER, Bruce (org.). 1976. Transaction and meaning: directions in the anthropology of exchange and human behavior. Philadelphia: ISHI Publications.

KELLY, Raymond. 1985. The Nuer conquest: a case study in the structure of non-equilibrium systems. Ann Arbor: University of Michigan Press. 
KIRKPATRICK, John T. 1977. "Person, hierarchy, and autonomy in traditional yapese theory". In: Dolgin; Kemnitzer \& Schneider (orgs.), Symbolic anthropology. New York: Columbia University Press. KRACKE, Waud H. 1978. Force and persuasion: leadership in an amazonian society. Chicago: University of Chicago Press.

LEACH, Edmund. 1954. Political systems of Highland Burma. Boston: Beacon Press.

. 1960. "The Sinhalese of the dry zone of Northern Ceylon". In: Dolgin; Kemnitzer \& Schneider (orgs.), Symbolic anthropology: social structure in Southeast Asia. London: Tavistock. . 1964. "Anthropological aspects of language: animal categories and verbal abuse". In: E. H. Lenneberg (org.), New directions in the study of language. Cambridge: MIT Press.

. 1966. Rethinking anthropology. London School of Economics Monographs on Social Anthropology, $\mathrm{n}^{\circ} 22$. New York: Humanities Press. . 1969. Genesis as myth and other essays. London: Jonathan Cape. . (org.). 1967. The structural study of myth and totemism. London: Tavistock.

LÉVI-STRAUSS, Claude. 1963. "The effectiveness of symbols". In: C. Jacobson \& B. G. Schoepf, trad., Structural anthropology. New York: Basic Books. . 1964-71. Mythologiques (introduction to a science of mythology). 4 vols. Paris: Plon.

. 1967. "La geste d'Asdiwal". In: Leach, E. (org.), Structural study of myth and totemism. Cidade: London: Tavistock.

LEVY, Robert. 1973. Tahitians: mind and experience in the society islands. Chicago: University of Chicago Press.

LEWIS, Gilbert. 1977. "A mother's brother to a sister's son". In: I. Lewis (org.), Symbols and sentiments. London: Academic Press.
MARRIOTT, McKim. 1976. "Hindu transactions: diversity without dualism". In: Kapferer (org.), Transaction and meaning. Michigan University: Institute for the Study of Human Issues. MEEKER, Michael E. 1979. Literature and violence in North Arabia. Cambridge: Cambridge University Press.

MOORE, Sally Falk \& MYERHOFF, Barbara G. (orgs.). 1975. Symbols and politics in communal ideology. Ithaca, New York: Cornell University Press.

MUNN, Nancy. 1969. "The effectiveness of symbols in murngin rite and myth". In: R. Spencer (org.), Forms of symbolic action. Seattle: University of Washington Press.

MYERHOFF, Barbara G. 1974. Peyote hunt: the sacred journey of the huichol indians. Ithaca, New York: Cornell University Press.

NEEDHAM, Rodney. 1973a. "The left hand of the Mugwe: an analytical note on the structure of meru symbolism". In: (org.), Right and left: essays on dual symbolic classification. Chicago and London: University of Chicago Press. . 1973b. Right and left: essays on dual symbolic classification. Chicago: University of Chicago Press.

O'LAUGHLIN, Bridget. 1974. "Mediation of a contradiction: why mbum women do not eat chicken". In: M. Rosaldo \& L. Lamphere (orgs.), Woman, culture and society. Stanford: Stanford University Press.

OlLMAN, Bertell. 1971. Alienation: Marx's conception of man in capitalist society. Cambridge: Cambridge University Press.

ORTNER, Sherry B. 1975. "Gods' bodies, gods' food: a symbolic analysis of a sherpa ritual". In: R. Willis (org.), The interpretation of symbolism. London: Malaby Press. . 1978. Sherpas through their rituals. Cambridge: Cambridge University Press. 
. 1981. "Gender and sexuality in hierarchical societies: the case of polynesia and some comparative implications". In: S. Ortner \& H. Whitehead (orgs.), Sexual meanings. Cambridge: Cambridge University Press.

1989. High religion: a cultural and political history of sherpa buddhism. Princeton: Princeton University Press.

PARSONS, Talcott. 1949 [1937]. The structure of social action. New York: The Free Press of Glencoe.

. \& SHILS, Edward A. (orgs.). 1962 [1951]. Toward a general theory of action. New York: Harper and Row.

PAUL, Robert A. 1982. The tibetan symbolic world: psychoanalytic explorations. Chicago: University of Chicago Press.

PIDDOCKE, Stuart. 1969. "The potlatch system of the southern kwakiutl: a new perspective". In: A. P. Vayda (org.), Environment and cultural behavior. Austin: University of Texas Press.

RABINOW, Paul. 1975. Symbolic domination: cultural form and historical change in Morocco. Chicago: University of Chicago Press.

. 1977. Reflections on fieldwork in Morocco. Berkeley: University of California Press.

RABINOW, Paul \& SULLIVAN, William M. 1979. "The interpretive turn: emergence of an approach". In: Interpretive social science, a reader. Berkeley: University of California Press.

RAPPAPORT, Roy A. 1967. Pigs for the ancestors. New Haven: Yale University Press.

RIEGELHAUPT, Joyce. 1978. "The revolt of Maria da Fonte: peasants, 'women' and the state". Ms.

RIESMAN, Paul. 1977. Freedom in fulani social life: an introspective ethnography. Chicago: University of Chicago Press.
ROSALDO, Michelle Z. 1980. Knowledge and passion: ilongot notions of self and social life. Cambridge: Cambridge University Press. . 1981. "Towards an anthropology of self and feeling". Ms.

ROSALDO, Renato. 1980. Ilongot headhunting, 1883-1974. Stanford: Stanford University Press.

ROSEN, Lawrence. 1978. "The negotiation of reality: male-female relations in Sefrou, Morocco". In: L. Beck $\&$ N. Keddie (orgs.), Women in the muslim world. Cambridge: Harvard University Press.

ROSS, Eric B. (org.). 1980. Beyond the myth of culture: essays in cultural materialism. New York and London: Academic Press.

SAHLINS, Marshall, 1964. "Culture and environment". In: S. Tax, (org.), Horizons of anthropology. Chicago: Aldine. . 1972. Stone age economics. Chicago: Aldine.

. 1981. Historical metaphors and mythical realities: structure in the early history of the Sandwich Islands Kingdom. Ann Arbor: University of Michigan Press.

SAHLINS, Marshall \& SERVICE, Elman R. (orgs.). 1960. Evolution and culture. Ann Arbor: University of Michigan Press.

SAID, Edward W. 1979. Orientalism. New York: Vintage.

SCHNEIDER, David M. 1968. American kinship: a cultural account. Englewood Cliffs, New Jersey: Prentice-Hall. . 1977. "Kinship, nationality and religion in american culture: toward a definition of kinship". In: Dolgin, Kemnitzer \& Schneider (orgs.), Symbolic anthropology. New York: Columbia University Press.

SCHNEIDER, Jane. 1978. "Peacocks and penguins: the political economy of european cloth and colors". American Ethnologist, 5(3):413-47. 
\& SCHNEIDER, Peter. 1976. Culture and political economy in Western Sicily. New York: Academic Press.

SERVICE, Elman, R. 1958. Profiles in ethnology. New York: Harper and Row.

SINGER, Milton. 1980. "Signs of the self: an exploration in semiotic anthropology". American Anthropologist, 82(3):485-507.

STEWARD, Julian H. 1953. "Evolution and process". In: A. L. Kroeber (org.), Anthropology today. Chicago: University of Chicago Press. . 1955. Theory of culture change. Urbana: University of Illinois Press.

TAMBIAH, Stanley J. 1968. "The magical power of words". Man, 3(2):175-208. . 1969. "Animals are good to think and good to prohibit". Ethnology, 8(4):423-59.

TAUSSIG, Michael T. 1980. The devil and commodity fetishism in South America. Chapel Hill: University of North Carolina Press.

TERRAY, Emmanuel. 1972. Marxism and "primitive" societies. Mary Klopper, trad. New York: Monthly Review Press.

. 1975. "Classes and class consciousness in the Abron Kingdom of Gyaman". In: M. Bloch, (org.), Marxist analyses and social anthropology. New York: John Wiley and Sons.

THOMPSON, E. P. 1966. The making of the english working class. New York: Vintage. . 1978. The poverty of theory and other essays. New York: Monthly Review Press.

TURNER, Terence S. 1969. "Oedipus: time and structure in narrative form". In: R. Spencer (org.), Forms of symbolic action. Seattle: University of Washington Press.

TURNER, Victor. 1967. The forest of symbols. Ithaca, New York: Corell University Press.
_ 1969. The ritual process. Chicago: Aldine.

WAGNER, Roy. 1975. The invention of culture. Chicago: University of Chicago Press.

WALLACE, Anthony F. C. 1980. Rockdale: the growth of an american village in the early industrial revolution. New York: W. W. Norton.

WALLERSTEIN, Emmanuel. 1976. The modern world system. New York: Academic Press.

WHITE, Leslie A. 1943. "Energy and the evolution of culture". American Anthropologist, 45(3):335-56. 1949. The Science of culture. New York: Farrar Straus.

WILLIAMS, Raymond. 1973. The country and the city. New York: Oxford University Press. . 1976. Keywords: a vocabulary of culture and society. New York: Oxford University Press. 1977. Marxism and literature. Oxford: Oxford University Press.

WOLF, Eric R. 1969. Peasant wars of the twentieth century. New York: Harper and Row.

. 1980. "They divide and subdivide and call it anthropology". New York Times, Ideas and Trends Section, p. E9, 30. November.

WORSLEY, Peter. 1968. The trumpet shall sound: a study of "cargo" cults in Melanesia. New York: Schocken.

YALMAN, Nur. 1969. "The structure of sinhalese healing rituals". In: R. Spencer (org.), Forms of symbolic action. Seattle: University of Washington Press.

YENGOYAN, A.A. 1979. "Cultural forms and a theory of constraints". In: A. L. Becker \& A. A. Yengoyan (orgs.), The imagination of reality. Norwood, New Jersey: Ablex. 